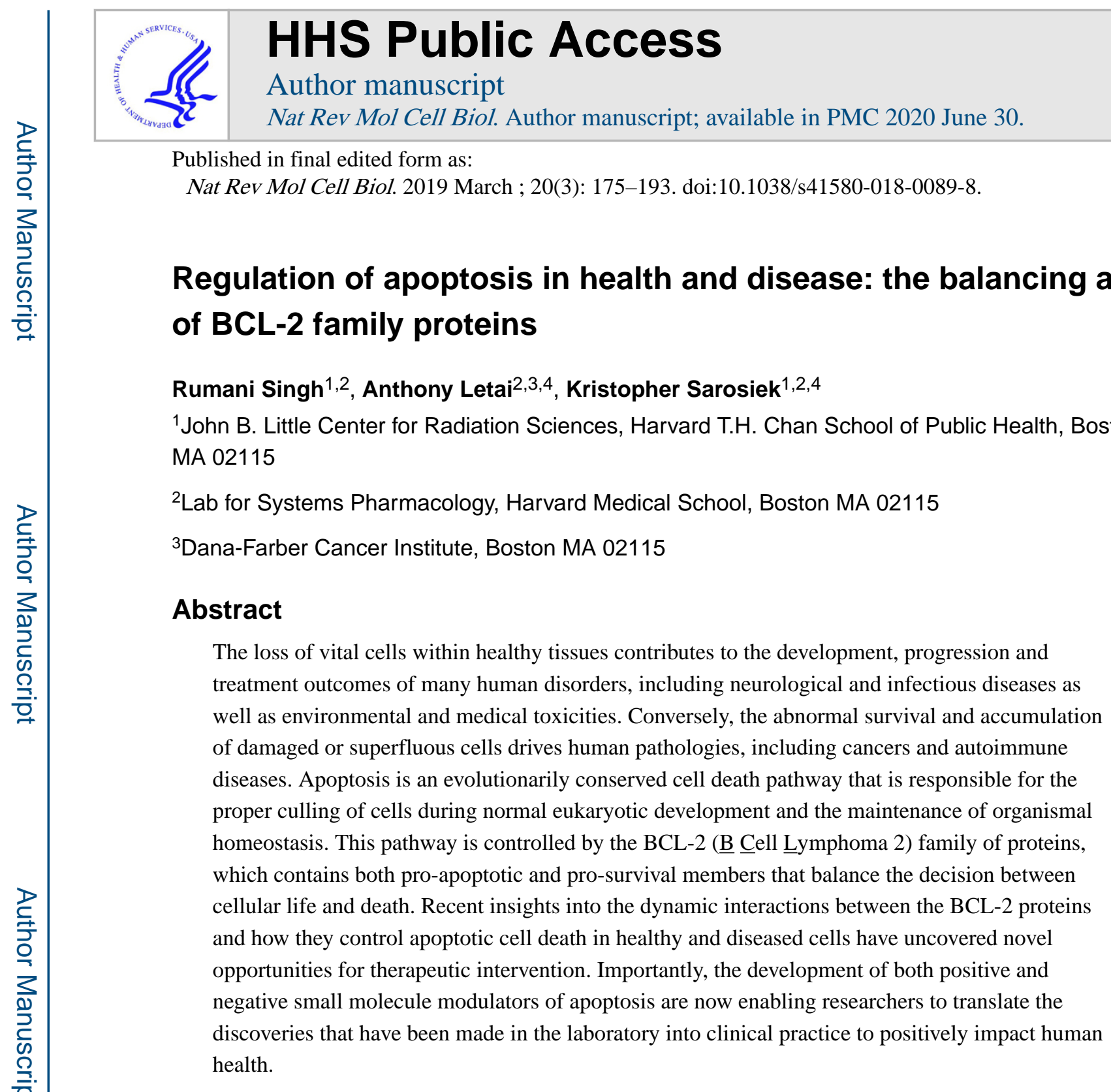

\title{
Introduction
}

In order for us to remain alive, certain cells within our bodies must die. To maintain normal physiology and tissue function, cells that are damaged, dysfunctional or no longer necessary are constantly cleared via regulated cell death and ideally replaced by new, healthy cells ${ }^{1-3}$. When these normal processes of cell death go awry, the consequences can be disastrous. Many of the diseases that constitute the leading causes of death and disability worldwide, including neurodegenerative, cardiovascular, autoimmune and infectious diseases involve either excessive or insufficient cell removal ${ }^{4,5}$. Furthermore, cytotoxic chemotherapies and ionizing radiation can induce cell death in healthy tissues, limiting the use of these potentially curative cancer therapies, especially in paediatric patients ${ }^{6-8}$. Despite the

${ }^{4}$ Co-corresponding authors: K. S. sarosiek@hsph.harvard.edu; A. L. Anthony_Letai@dfci.harvard.edu. Author contributions: All authors researched data for the article and wrote the article. All authors contributed to discussion of the content and reviewed and/or edited the manuscript before submission. 
undeniable importance of maintaining the survival of our healthy cells or eliminating those that are damaged or potentially dangerous, our understanding of cell death processes and their regulation is still nascent, especially in light of recent findings demonstrating the dynamic nature of cell death regulation during development, aging and disease.

The apoptosis pathway is evolutionarily conserved across metazoans. In vertebrates, apoptosis is important for proper development ${ }^{9,10}$, maintenance of tissue homeostasis ${ }^{11,12}$ and cancer prevention ${ }^{13}$. Apoptotic cell death is associated with several conserved features (Supplementary Box 1) and culminates in the activation of cysteine-aspartic proteases (caspases) which degrade cellular components to prepare dying cells for clearance by phagocytes with minimal stress to surrounding cells and tissues ${ }^{14-17}$. Importantly, in contrast to necrosis (an unregulated form of cell death frequently resulting from acute cell trauma ${ }^{18}$ ), apoptosis requires energy input and thus is an active process. In more detail, apoptosis is initiated by either internal or external stimuli and mediated via two distinct pathways: the intrinsic pathway (mitochondria-mediated, a focus of this Review), and the extrinsic pathway (death receptor [G]-mediated; see Supplementary Box 2).

The key to the regulation and execution of intrinsic apoptosis are BCL-2 ( $\underline{B}$ Cell Lymphoma 2) family proteins, which include both pro-apoptotic and pro-survival (anti-apoptotic) members (Fig. 1). The careful modulation of the balance between these two groups of BCL-2 proteins can largely determine cell fate decisions between life and death.

The state of apoptosis research today is particularly exciting given the recent development of BH3 mimetics - small molecules that mimic the activity of selected pro-apoptotic proteins and thus can sensitize cells to mitochondrial apoptosis (Fig. 1). Several different BH3 mimetics, targeting various BCL-2 proteins have been developed and are being explored as potential therapeutics in pathological conditions caused by insufficient or excessive apoptosis (Box 1). These agents have already demonstrated potent clinical utility for the treatment of blood cancers, including chronic lymphocytic leukaemia and acute myelogenous leukaemia, but their potential uses in other diseases, as discussed in this Review, are less established but nonetheless promising.

In this Review we discuss the regulation of apoptosis by the members of the BCL-2 family of proteins, including the modulation of BCL-2 proteins themselves in mammalian physiology as well as deregulation of BCL-2 protein balance in various pathologies. Although many other forms of cell death have been discovered and described, the intrinsic apoptosis pathway is physiologically dominant, leading to the demise of over 60 billion of our cells each day ${ }^{19}$ and thus will be the sole focus of this Review.

\section{Intrinsic pathway of apoptosis}

Apoptosis is the most studied form of cell death and also the primary mode of cell death involved in development and homeostasis ${ }^{18,20}$. Here we describe the execution of apoptotic cell death via the intrinsic pathway, focusing on the dynamic regulation of the process by BCL-2 proteins. 


\section{BCL-2 proteins as regulators of intrinsic apoptosis.}

BCL-2 proteins are the key regulators of the intrinsic apoptosis pathway. Each member of this family contains one or more of BCL-2 homology (BH) domains, BH1-BH4. Apoptosis is triggered by pro-apoptotic, $\mathrm{BH}$-only proteins, the name of which stems from the fact that these proteins contain only a single BH domain, in this case BH3. The key effectors of apoptosis commitment are BH3-only "activator" proteins ${ }^{21}$ : BIM (BCL-2-interacting mediator of cell death; encoded by BCL2L11), BID (BH3-interacting domain death agonist; encoded by $B I D$ ), PUMA (p53 upregulated modulator of apoptosis; encoded by $B B C 3$ ) and potentially others (see below), which bind and activate either or both of the pro-apoptotic pore-forming proteins BAX (BCL-2-associated X protein; encoded by $B A X$ ) or BAK (BCL-2 antagonist/killer; encoded by $B A K 1$ ). The activation of BAX or BAK at the mitochondrial surface results in an allosteric change in these proteins, allowing them to oligomerize and form macro-pores in this membrane, causing mitochondrial outer membrane permeabilization (MOMP).

MOMP results in the release of apoptogenic proteins from the intermembrane space (Fig. 1). In the cytoplasm, released mitochondrial proteins are involved in caspase activation either directly - as is the case for cytochrome c [G], which binds to a scaffold protein APAF1 (apoptotic protease-activating factor 1 ) to form the apoptosome [G] , or indirectly - as exemplified by SMAC [G] $]^{22}$ and serine protease OMI (also known as HTR2A), which neutralize caspase-inhibitory proteins such as inhibitor of apoptosis XIAP [G]. These events promote the activation of the initiator caspase (caspase 9) and executioner caspases (caspases 3,6 and 7) for dismantling of the cell. Note that although caspase activation is a largely ubiquitous downstream event in apoptotic cell death, it is not the main commitment point for apoptosis since the prevention of caspase activation does not, under typical physiological circumstances, rescue dying cells post-MOMP ${ }^{23,24}$. This may explain why previous efforts to use caspase inhibitors in cells that are undergoing apoptosis to maintain tissue function were largely unsuccessful - cells with permeabilized mitochondria cannot continue to function metabolically and thus caspase inhibition only delays some of the morphological and biochemical changes that are observed post-MOMP in dying cells (see Supplementary Box 1). Overall, MOMP is the critical step at which a cell irreversibly commits to undergoing apoptotic cell death ${ }^{25}$ and represents a cellular 'point of no return'. If, however, the commitment to MOMP is incomplete (only a minor subset of mitochondria undergo MOMP $)^{26,27}$, cells may prevent more widespread activation of BAX or BAK and retain their clonogenic potential. Interestingly, cells with so-called 'minority MOMP' can be potentially tumorigenic, owing to the activity of post-MOMP activated proteins such as DNAses that may mutate DNA to facilitate neoplastic transformation ${ }^{27,28}$.

A new detail in this pathway has recently emerged: apart from causing the release of mitochondrial proteins, BAX/BAK macropores in the mitochondrial membrane also facilitate the release of mitochondrial DNA into the cytoplasm where, in the absence of capsases $^{29}$, it can activate pro-inflammatory signalling, likely via the activation of cGASSTING [G] signalling ${ }^{30,31}$. This finding has possible implications for cancer immunotherapy - the activation of cGAS-STING signalling can activate an anti-cancer immune response ${ }^{32}$. Presumably, blocking downstream caspase activity in cancers that are undergoing 
mitochondrial apoptosis in response to therapy may greatly facilitate the activation of cGASSTING signalling and production and release of type-I interferons, which serve as DAMPs $[\mathbf{G}]^{33}$ to encourage an anti-cancer immune response.

Countering this pro-apoptotic chain of events are the pro-survival (anti-apoptotic) BCL-2 family proteins: BCL-2 (B cell lymphoma 2; encoded by BCL2) BCL-X $\mathrm{L}_{\mathrm{L}}$ (B cell lymphoma extra large; encoded by BCL2L1), BCL-W (B cell lymphoma w; encoded by BCL2L2), BFL1 (BCL2-related isolated from fetal liver 1; also known as A1; encoded by BCL2A1) and MCL1 (Myeloid cell leukaemia 1; encoded by $M C L 1$ ). These proteins contain all $\mathrm{BH}$ domains (BH1-BH4) and can block apoptosis by binding and sequestering monomeric activated BAX or BAK or BH3-only activator or sensitizer (see below) proteins ${ }^{34}$ (Fig. 1 and Fig. 2). These specific interactions occur via the binding of the hydrophobic face of the BH3 domain on the pro-apoptotic protein into a hydrophobic groove formed by the BH1-BH3 domains on the anti-apoptotic protein. In order for apoptosis to occur, pro-survival proteins within the cell must be overwhelmed and BAX and/or BAK activated. This is where the balance between pro-survival and pro-apoptotic BH3-only proteins comes into play.

To date, at least 8 different $\mathrm{BH} 3$-only proteins have been discovered and validated to have canonical pro-apoptotic activity (binding and modulating the activity of pro-survival BCL-2 family proteins and/or BAX/BAK) in mammalian cells. These proteins include BIM, BID, BAD (BCL2 associated agonist of cell death; encoded by BAD), BIK (BCL2 interacting killer; encoded by $B I K$ ), BMF (BCL-2 modifying factor; encoded by $B M F$ ), Hrk (Harakiri; encoded by $H R K$ ) [G], Noxa (Latin for damage, also known as PMA-induced protein 1; encoded by PMAIPI) and PUMA. Of these, BIM, tBID (truncated and active form of BID, generated by caspase-mediated cleavage) and PUMA are most potent at activating BAX and $\mathrm{BAK}^{21,35-38}$. Due to their less efficient activation of BAX or BAK, the remaining BH3-only proteins are referred to as 'sensitizers' and their main function is considered to be in the inhibition of pro-survival proteins ${ }^{21,39}$. Each of these 8 proteins contain a single, 9-13 amino acid BH3 domain, which is required for their interactions with pro-survival BCL-2 proteins and/or with $\mathrm{BAX}$ or $\mathrm{BAK}^{40}$. This binding is highly selective and $\mathrm{BH} 3$-only proteins have varying binding affinities for different pro-survival and/or pro-apoptotic effector

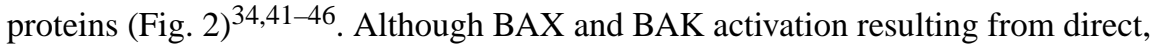
detectable ${ }^{35,47}$ interactions with activator BH3-only proteins is a widely-accepted view of apoptosis induction, recent work demonstrating BAX and BAK activation even in the absence of all known BH3-only proteins ${ }^{48}$ suggests that other direct activators may exist (including the mitochondrial outer membrane itself) when all pro-survival proteins are inactivated.

\section{Apoptosis initiators.}

Intrinsic apoptosis can be triggered by diverse stimuli including genotoxic damage (i.e. ionizing radiation ${ }^{46,49}$, DNA-targeting cytotoxic chemotherapies ${ }^{50}$ ), damage to cellular organelles or signalling platforms (ER stress $[\mathbf{G}]^{51,52}$, mitochondrial damage ${ }^{53}$, inhibition of intracellular signalling pathways ${ }^{54}$ ), excessive mitogenic stimulation (activation-induced cell death [G] ${ }^{55,56}$ ) or oncogene-induced cell death ${ }^{57}$ (of note, this type of cell death has been thoroughly established only for the c-Myc oncogene and the activation of other mitogenic 
oncogenes may increase apoptotic sensitivity of cells, but potentially only through the requisite activation of c-Myc for cell growth and proliferation $\left.{ }^{46,57-61}\right)$ ). Cells may be driven into apoptosis even by the lack of proper stimulus (i.e. growth factor withdrawal ${ }^{62}$, nutrient deprivation $^{63}$ ) (Fig. 1). The diversity in apoptosis initiators is mirrored by the diversity in the levels and types of pro-apoptotic effectors unleashed as highlighted below. For example,

DNA damage from ionizing radiation or genotoxic chemotherapeutics induces apoptosis by activating p53 to drive transcription of its target genes including BAX, PUMA and Noxa $^{64,65}$ and repression of BCL-2 (Fig. 2a). This contrasts with apoptosis induced by kinase inhibition or growth factor withdrawal, which involves activation of $\mathrm{BIM}^{66,67}$, BAD (via dephosphorylation ${ }^{68}$ ), $\mathrm{BMF}^{69}$ and $\mathrm{Hrk}^{70}$. The specificity of these responses may potentially be leveraged to control cell fate decisions in cells that are damaged or stressed.

\section{BCL-2 protein levels and apoptotic priming.}

Proteins of the BCL-2 family are regulated by multiple mechanisms (Box 2) and their expression levels widely differ depending on tissue type, cell lineage, developmental stage, organismal age and any stress or damage that is experienced (Fig. 3) $)^{46,71}$. The balance between pro-apoptotic and pro-survival proteins determines whether a cell will live or die $^{66,72-74}$. To illustrate, a cell that maintains its survival by expressing only enough prosurvival proteins to barely buffer existing pro-apoptotic proteins is considered primed for apoptosis (Fig. 2b). A primed cell readily undergoes MOMP in response to even a weak proapoptotic signal, which can be elicited by cellular stress or damage. A cell that expresses a surplus of pro-survival proteins that can buffer against existing and potentially additional pro-death molecules is less primed, or unprimed. Finally, a cell that does not express sufficient levels of the key pore-forming proteins BAX and BAK are unable to undergo MOMP (and therefore unable to die via the mitochondrial apoptosis pathway, but may still be able to die via the extrinsic apoptosis pathway - see Supplementary Box 2) and are designated as apoptosis refractory. While expressed here categorically for illustration, priming exists on a continuum and cells can exist at any point along this scale. Recently, a functional assay called BH3 profiling was developed (Box 3), which measures apoptotic $\operatorname{priming}^{72,75}$.

\section{Apoptosis pathway in physiology}

An important mechanism that ensures organismal homeostasis is the removal of damaged or superfluous cells via apoptosis and in the former case their replacement from stem cellderived progeny. Although not absolutely essential for animal development or survival, apoptotic competence ensures proper tissue development and homeostasis (Fig. 3).

\section{Heightened apoptotic sensitivity as a hallmark of developing tissues.}

Development is associated with high cell proliferation. Apoptosis has long been considered essential for normal development ${ }^{76,77}$ by allowing for the removal of superfluous or damaged cells generated as a result of this high proliferation as well as to shape tissues by removing unwanted cells. However, mounting evidence supports the view that although apoptotic cell death has a major role in proper organ and limb formation, cell specialization and differentiation, it is not absolutely essential for mammalian development. Although mice 
lacking both BAX and BAK have profound resistance to apoptosis and exhibit phenotypes indicative of loss of developmental apoptosis, such as interdigital webbing and imperforate vaginas (see also below), they are able to survive into adulthood if they successfully pass the crucial perinatal period at which the vast majority of double-knockout mice die, reportedly due to difficulties with proper feeding ${ }^{10,78}$. It is possible that the extrinsic apoptosis pathway or another pro-apoptotic, pore-forming protein, such as the non-canonical BCL-2 family member BOK (BCL-2-related ovarian killer; encoded by $B O K$ ) replaces the need for BAX and BAK during development. Indeed, the loss of BOK has been recently shown to exacerbate the phenotypes associated with loss of BAX and BAK ${ }^{10}$ and to phenocopy many of the profound abnormalities of Apaf1 knockout mice, which are considered completely null for intrinsic apoptosis due to the inability to form functional apoptosomes ${ }^{79}$. However, a small subset of triple knockout mice for Bax, Bak1 and Bok are able to survive to adulthood (similarly to Apaf1 knockout mice), highlighting that although intrinsic apoptosis is important for proper development, it is not absolutely essential for mammalian life. In addition, a recent report showed that concomitant loss of autophagy-regulating protein ATG5 made phenotypes associated with Bax/Bak1 double knockout even more pronounced, implying that autophagic cell death may compensate for loss of the competence for intrinsic apoptosis ${ }^{80}$.

Despite this, apoptosis is important for the optimal formation and maturation of tissues and organs. For instance, perinatal brain development is associated with massive proliferation of neural progenitors ${ }^{81}$, followed by a wave of apoptosis that eliminates approximately half of cells that are either excessive or have not established appropriate synaptic connectivity ${ }^{82}$. The death of neuronal cells during this period is almost entirely BAX-dependent as demonstrated by the accumulation of excess neurons in Bax (but not Bakl) knockout animals ${ }^{78,83}$ as well as BCL-2 overexpressing animals (Fig. 3) ${ }^{62}$. Apart from BAX, also other pro-apoptotic proteins, including BIM and BID are highly expressed in the developing brain. Importantly, the high expression of pro-apoptotic proteins that facilitates neuronal pruning also renders the developing brain highly sensitive to pro-apoptotic signalling (Fig. 3 ) and so this tissue is classified as "primed for apoptosis" by BH3 profiling (Box 3) ${ }^{46}$. The extremely high apoptotic sensitivity of the developing brain is likely responsible for the hypersensitivity of this tissue to sources of damage or stress, including chemotherapy or ionizing radiation at this stage of life ${ }^{46,84,7,85}$. Importantly, pro-apoptotic proteins are strongly downregulated after the early postnatal period and thus protect terminally differentiated and largely irreplaceable neurons from unwanted apoptosis later in life (Fig. 3). In fact, we propose that the increased sensitivity of the developing brain to a great variety of environmental toxins (such as lead ${ }^{86}$ or arsenic ${ }^{87}$ ) or medically necessary agents (anaesthetics ${ }^{88}$, glucocorticoids ${ }^{89}$ ) as well as perinatal injuries (ischaemia-reperfusion injury $[\mathbf{G}]^{90}$, traumatic brain injuries ${ }^{91}$ ) may be due to its increased propensity of developing neuronal cells to undergo apoptosis as compared to adults.

Due to the high expression of pro-apoptotic proteins in the developing brain ${ }^{46,77}$, this tissue is dependent on the expression of the pro-survival protein BCL- $\mathrm{X}_{\mathrm{L}}$ to keep these deathinducing proteins balanced. In fact, knockout of the pro-survival gene Bcl211 (encoding BCL- $\mathrm{X}_{\mathrm{L}}$ ), results in embryonic lethality due to massive cell loss within the developing 
central nervous system (as well as in the haematopoietic system) ${ }^{92}$, thus highlighting the tight regulation of apoptosis during neurogenesis and development.

The heightened apoptotic sensitivity of tissues during development is not limited to the brain. The heart, kidneys and liver are also more sensitive to pro-apoptotic stimuli at perinatal and early postnatal stages than in adults ${ }^{46,77}$. Importantly, this heightened apoptotic sensitivity is frequently associated with active proliferation of tissues and expression of the growth- and division-supporting transcription factor c-Myc, suggesting that active proliferation is tightly coupled to expression of the machinery necessary for apoptosis induction. c-Myc actively drives the transcription of prominent pro-apoptotic genes including BAX, BID and BIM in proliferating tissues, promoting a state of high susceptibility to apoptosis ${ }^{46,93}$. Note that this process is also active in cancers, as discussed below. A major exception to this rule linking high proliferation with high apoptotic sensitivity are peripheral resting $\mathrm{B}$ and $\mathrm{T}$ lymphocytes, which are not actively cycling but are extremely primed for apoptosis and, consequently, are highly sensitive to many types of cytotoxic chemotherapies and ionizing radiation ${ }^{94}$ (see also next sub-section).

The normal development of germ cells and reproductive tissues is also highly dependent on balanced regulation of mitochondrial apoptosis by BCL-2 family proteins, potentially serving to eliminate male germ cells that carry genetic dysfunctions in apoptosis. For instance, Bax knockout ${ }^{11}$ (as well as knockout of multiple other pro-apoptotic genes such as Apaf1 (ref. ${ }^{79}$ ) or overexpression of pro-survival MCL1(ref. ${ }^{95}$ ), BCL-2 or BCL-X ${ }_{\mathrm{L}}{ }^{96}$ ) impairs germ cell differentiation, resulting in male sterility. Although this process is incompletely understood, it seems that blocking the naturally occurring apoptosis that regulates germ cell number leads to an imbalance of germ cells with supporting Sertoli cells [G], which leads to massive loss of germ cells via a non-apoptotic cell death (Fig. 3). In female mice, blocking apoptosis via deletion of $\mathrm{BAX}$ and $\mathrm{BAK}^{78}$ or overexpressing BCL-2 (ref. ${ }^{97}$ ) prevents the normal hormonally-driven opening of the vaginal cavity to the skin at 5 weeks of age, impinging on their reproductive capacity.

The role of MCL1 in mammalian development is less clear than BCL-2 or BCL- $\mathrm{X}_{\mathrm{L}}$ due to the very early (at embryonic day 3.5) lethality of this knockout, which is associated with a trophectoderm defect that impairs implantation of the embryo ${ }^{98}$. Although this early lethality may be due to a strong requirement for MCL1 in counteracting apoptosis, it may alternatively be due to potential physiological roles of MCL1 beyond regulating apoptosis: it has been shown that an amino-terminally truncated isoform of MCL1 is imported into the mitochondrial matrix where it facilitates respiration and ATP production ${ }^{99,100}$. However, in cancer cells, the loss of MCL1 has no major impact on cell growth beyond regulating apoptosis $^{48}$. It is still entirely possible that any non-apoptotic functions of MCL1 may only be detected in certain contexts, especially in non-transformed cells that are less proficient at adapting to changing growth conditions.

As many tissues mature and reach a largely post-mitotic state, most apoptosis-regulating proteins (both those that are pro-survival as well as pro-apoptotic) are strongly downregulated to foster apoptosis resistance ${ }^{46,77,7}$. Although the aetiology of this downregulation is unclear, it ostensibly prepares non-replaceable cells for life-long survival 
by removing the proteins that can potentially cause their demise. It is possible that the apoptosis pathway becomes re-activated in certain physiological or pathological circumstances, including those mentioned below in disease-specific settings such as neurodegenerative disorders.

\section{Importance of apoptosis for tissue homeostasis.}

In mammals, the blood system contains multiple types of differentiated cells with highly specialized functions. Many types of mature blood cells are extremely short-lived and are replaced at an estimated rate of more than 60 million cells per minute in an adult human. For example, neutrophils - the most common nucleated cell type in the peripheral blood have a lifespan of only 5.4 days ${ }^{101}$, meaning that roughly $20 \%$ of neutrophils die via apoptosis each day in an adult human. The short half-life of these cells is likely due to their prominent role as phagocytes for invading pathogens - mammals have presumably evolved to allow these cells (together with their microbial load) to self-destruct via apoptosis and be replaced instead of utilizing a detoxification strategy. Interestingly, a similar mechanism of self-destruction exists in hepatocytes within the liver, which accumulate toxins and undergo apoptosis. Apoptotic hepatocytes release cytokines, which stimulate liver regeneration and hepatocyte proliferation allowing the tissue to recover ${ }^{102}$.

The continuous death of neutrophils requires the constant proliferation of haematopoietic progenitor cells (HPCs) and, upstream, haematopoietic stem cells (HSCs). The continuous yet variable proliferation of these cells is correlated with their levels of apoptotic priming: the higher rates of proliferation in more differentiated progenitors ${ }^{103}$ are associated with higher levels of priming ${ }^{104}$. Similarly, HSCs in young animals are more primed for apoptosis than in aged individuals, which corresponds with higher proliferative potential of young $\mathrm{HSCs}^{104}$. Strong evidence for the role of BCL-2 family proteins in maintaining homeostasis of the haematopoietic system can be observed in mouse models of apoptotic dysfunction. For example, Bax knockout, and especially Bax and Bak1 double knockout ${ }^{78}$, mice accumulate mature $\mathrm{T}$ and $\mathrm{B}$ lymphocytes ${ }^{11}$, which indicates that these cells, similarly to neutrophils, are normally cleared via apoptosis at the end of their useful lifespans, upon clearance of active infection, and during the maturation process in the thymus when autoreactive lymphocytes are removed (Fig. 3). In addition, genetic ablation or pharmacologic inhibition of BCL- $\mathrm{X}_{\mathrm{L}}$ causes accelerated apoptosis in platelets, which rely on BCL- $\mathrm{X}_{\mathrm{L}}$ to counteract their high apoptotic susceptibility ${ }^{105}$, causing thrombocytopenia and complicating the clinical translation of $\mathrm{BH} 3$ mimetics targeting this pro-survival protein for cancer treatment ${ }^{106}$ (see Box 1). These regulatory mechanisms have recently been reviewed elsewhere (see $\left.{ }^{107,108}\right)$.

Although some adult somatic cells within other tissues can die via apoptosis in response to genotoxic damage or other stress (for example, cells within the intestinal crypts ${ }^{109}$ ), the role of apoptosis in maintaining major organ systems beyond the haematopoietic system at steady state is less clearly defined ${ }^{110}$. For example, the knockout of Bax, Bak1, or Bok (or even all three ${ }^{10}$ ) genes has limited impact on the homeostasis of the gastrointestinal system, suggesting that apoptotic cell death is not a highly prominent feature of that tissue. However, the importance of apoptotic susceptibility may only become apparent when the tissue is 
damaged and requires repair or large-scale physiological remodelling, as is the case for mammary gland involution following lactation ${ }^{111}$. Indeed, cellular sensitivity to apoptosis changes during repair and regeneration ${ }^{46,112}$, highlighting the link between tissue proliferation and apoptotic competence. For example, in the liver, hepatocyte loss due to alcohol toxicity, viral infection or excessive fatty acids ${ }^{113}$ can stimulate surviving hepatocytes to proliferate and regenerate lost tissue, which is associated with the upregulation of c-Myc and its pro-apoptotic targets in dividing cells (Fig. 3). In this proliferative state hepatocytes are transiently sensitized to apoptosis ${ }^{46}$ and potentially are more vulnerable to cell death in the event of a subsequent insult (Fig. 2b).

\section{Suppression of apoptosis in disease}

As with many other biological, physical and chemical systems within complex organisms, apoptotic cell death is kept in a crucial balance to maintain equilibrium. When cells that are intended to die by apoptosis fail to do so, they can accumulate and cause detriment to the host via several distinct mechanisms, several of which are outlined below.

\section{Cancer cell survival.}

There is no other set of diseases in which apoptosis has been better characterized than cancers. In fact, the namesake of this family, BCL-2, was named for its discovery in B-cell lymphomas, where BCL-2 is frequently grossly overexpressed ${ }^{114}$. In addition, the ready access to clinical material and widespread use and utility of in vitro cancer cell lines has greatly accelerated studies of apoptosis regulation in this disease.

Because it is associated with accumulating DNA damage, aberrant growth signals and excessive pressure to support cell growth, the transformation of a cell to a malignant state is inherently stressful ${ }^{115,116}$. In addition, many of the genes necessary for active growth and proliferation are controlled by c-Myc, which is therefore unsurprisingly deregulated in nearly all cancers ${ }^{117}$. This, however, comes with the cost of increased expression of proapoptotic genes, which are also controlled by c-Myc, resulting in heightened apoptotic priming and frequent apoptosis of pre-malignant cells (Fig. 4). The evasion of apoptosis at this stage of cellular transformation is vital for the continued proliferation of cancer cells and tumour formation, and the ability to suppress apoptosis is referred to as one of the hallmarks of cancer ${ }^{118}$. Indeed, blocking apoptosis has been shown across many model systems to facilitate malignant transformation and cancer development ${ }^{119,120}$. The means by which cells evade apoptosis vary greatly among cancer types and even within the same cancer type, resulting in heterogeneous expression of and dependence on pro-survival BCL-2 family proteins. This topic has been recently reviewed by several groups (see $74,121-123$ ) and will thus only be addressed briefly in this Review.

The need to actively suppress apoptotic cell death is particularly important for cancers that originate from the haematopoietic system (which as discussed above is particularly primed for apoptosis) and the expression of BCL-2 family members is frequently altered in these cancers. The mechanisms most typically employed include: upregulation of pro-survival proteins including BCL-2, MCL1, BCL- $\mathrm{X}_{\mathrm{L}}, \mathrm{BFL} 1$ and BCL-W; downregulation or inactivation of pro-apoptotic proteins including BIM, BID, BAX, Noxa, PUMA, and Hrk via 
mutation (observed only rarely ${ }^{124}$, potentially owing to the large protein-protein interaction surfaces found in BCL-2 family proteins, which are not effectively blocked by mutations), phosphorylation ${ }^{69,125}$ or other post-translational ${ }^{126}$ or post-transcriptional ${ }^{98}$ mechanisms; or downregulation or inactivation of the pore-forming proteins BAX and BAK (Fig. 4). Interestingly, aged HSCs in mammals are less adept at repairing DNA damage and, as discussed above, they are also less primed for apoptosis than younger counterparts ${ }^{104}$. These mechanisms may contribute to the outgrowth and survival of malignant clones in the haematopoietic system and may provide a mechanistic basis for the large increases in prevalence of most lymphomas and leukaemias as we age ${ }^{127}$.

Cancer cells must only suppress enough pro-apoptotic signalling via the above mechanisms to maintain survival during daily fluctuations in nutrient and environmental stressors and so generally they remain highly primed for apoptosis when unchallenged by exogenous perturbations. Thus, the evasion of apoptosis during carcinogenesis does not necessarily yield an apoptosis resistant cell and for this reason, cancer cells, and in particular those of the haematopoietic origin, show high sensitivity to cytotoxic chemotherapy and ionizing radiation ${ }^{72,73,116,128,129}$ (Fig. 4). However, cancer cells can develop further resistance to these treatments (including via one of the aforementioned mechanisms,) and for too many patients, the inability to eradicate $100 \%$ of malignant cells results in the selection and expansion of such resistant cells and thus drives therapy resistance.

Although solid tumours frequently exhibit similar changes in BCL-2 family proteins as those listed above for haematologic malignancies, they typically employ fewer and less dramatic alterations in order to stave off apoptosis. This may be due to the inherently lower levels of apoptotic sensitivity evident in cells of non-haematologic lineages. For example, mature cells from the adult brain and kidneys are profoundly resistant to apoptosis ${ }^{46}$ and thus the malignant cells that emerge from those tissues (which likely originate from stem cells within the tissue but ostensibly share many lineage-associated characteristics such as apoptosis regulation) are likely to be more resistant to apoptosis as well. Furthermore, the genes that can drive proliferation in cancers are also tissue-type-specific ${ }^{130}$. This may help explain why solid tumours are, in general, less sensitive to chemotherapy and radiation therapy than haematopoietic cancers.

\section{Development of autoimmune diseases.}

Beyond cancer, the most compelling evidence of insufficient apoptosis contributing to disease is in autoimmune disorders. Although these defects may involve perturbations to the extrinsic pathway ${ }^{131}$, the intrinsic pathway is also implicated. For instance, mice lacking BIM $^{132}$ or overexpressing BCL-2 (ref. ${ }^{133}$ ) spontaneously produce auto-antibodies to nuclear antigens and develop a systemic autoimmune disease. In humans, abnormally high expression of BCL-2 in peripheral blood B and T lymphocytes has been observed in patients diagnosed with systemic lupus erythematosus (SLE) - a prototypic autoimmune disease characterized by inflammation and organ damage in association with the expression of autoantibodies against double-stranded DNA. Such high BCL-2 levels may be responsible for the survival of self-reactive lymphocytes driving SLE. 
Autoimmune lymphoproliferative syndrome (ALPS) is a recently-characterized disorder caused predominantly by inherited mutations in the gene that encodes Fas (tumor necrosis factor receptor superfamily member 6 , which is implicated in extrinsic apoptosis) leading to reduction in apoptosis potential and expansion of double negative T cells [G] (DNTCs) - a hallmark of ALPS. Although the accumulation of T cells due to dysfunctional Fas-mediated apoptosis does not directly involve BCL-2 family proteins, it has been reported that DNTCs frequently upregulate pro-apoptotic BIM, which is counteracted by the overexpression of at least one pro-survival BCL-2 family protein (BCL-2 or BCL- $\mathrm{X}_{\mathrm{L}}$ ). The important role of intrinsic apoptosis deregulation in ALPS is supported by the sensitivity of ALPS-associated DNTCs to BH3 mimetics ${ }^{103}$.

Finally, gastrointestinal autoimmune diseases such as Crohn's disease and ulcerative colitis are believed to occur as a consequence of chronic inflammation and consequent death of intestinal epithelial cells. This inflammation is established by hyper-proliferating $\mathrm{T}$ cells that normally would be eliminated by cell death ${ }^{134}$. However, in these conditions, an increase in pro-survival BCL-2 prevents T cell apoptosis.

\section{Propagation of intracellular pathogens.}

Pathogenic microorganisms must evade detection or must prevent the self-destruction of host's cells for a period long enough to replicate and spread. To accomplish this, certain types of infectious pathogens have evolved the ability to produce factors that suppress apoptosis. It is important to note that herein we focus exclusively on BCL-2 family proteins, yet virus-mediated and bacteria-mediated effects on the extrinsic apoptosis pathway, which is widely involved in responses to infection, are also common (reviewed in ${ }^{135,136}$ ).

One fourth of the world's population is infected with Mycobacterium tuberculosis, leading to over 10 million symptomatic illnesses and over 1.7 million deaths each year. Infection with $M$. tuberculosis initiates when lung macrophages phagocytize the bacteria in the alveolar spaces. Notably, the internalized bacteria are able to survive and replicate within these host cells. Once detected, the host attempts to use autocrine or paracrine signalling to trigger extrinsic apoptosis in infected macrophages. However, M. tuberculosis cell wall components enhance the activity of the nuclear receptor PPAR $\gamma$ (peroxisome proliferatoractivated receptor $\gamma$ ) to drive production of pro-survival protein MCL1, which inhibits both extrinsic and intrinsic apoptosis, thereby supporting further replication of the pathogen ${ }^{137}$. Finally, when the threshold of about 20 bacteria per cell is reached, the cell undergoes a form of cell death termed "high-MOI (multiplicity of infection) apoptosis ${ }^{137}$ ", which shares features of apoptosis and necrosis and may be the preferred mode of self-destruction from the perspective of pathogen spreading owing to the non-immunogenic nature of apoptotic cell death. Once released from the dying cells, the bacteria are able to infect additional cells and continue the cycle or spread to other individuals via aerosolized transmission. A similar mechanism is employed by Legionella pneumophila, which secretes a protein (phosphoinositide phosphatase SidF) into infected host cells that blocks the activity of several pro-apoptotic proteins to prevent the mitochondrial apoptosis that typically serves to limit pathogen expansion ${ }^{138}$. 
Similarly to intracellular bacteria, viruses require the host cells to replicate and thus must prevent their self-destruction upon detection of infection. Cytomeglovirus (CMV), for example, produces multiple proteins that suppress apoptosis, including viral mitochondrialocalized inhibitor of apoptosis (vMIA; also known as pUL37×1), which is structurally similar to BCL- $\mathrm{X}_{\mathrm{L}}$ despite its considerable sequence differences ${ }^{139}$. vMIA can block mitochondrial apoptosis via mechanisms reminiscent of $\mathrm{BCL}-\mathrm{X}_{\mathrm{L}}$, including the binding and sequestration of BAX at the mitochondrial membrane to block MOMP. In addition, a product of the $\mathrm{m} 41.1$ open reading frame of CMV encodes a mitochondria-localized inhibitor of BAK oligomerization (vIBO)), which in combination with vMIA completely inhibits the intrinsic apoptosis pathway ${ }^{139}$. Interestingly, CMV also causes ER stress during active infection and actively produces the viral protein UL38 to block ER stress-induced apoptosis. Similar mechanisms can be observed in cells infected with Epstein-Barr Virus (EBV) and Kaposi's sarcoma gamma-herpesviruses (KSHVs), which encode the prosurvival BCL-2 viral homologs: BHRF1 and KSHV-BCL-2, respectively, which can bind and sequester BIM ${ }^{140,141}$. In addition, the expression of the EBV-encoded latent membrane protein 1 (LMP1) upregulates expression of several pro-survival proteins including BCL-2, MCL1 and BFL1 (refs. ${ }^{142-144}$ ) to suppress apoptosis during viral replication, making it a promising therapeutic target for the treatment of EBV infection. Note that expression of these virally-associated pro-survival proteins can suppress apoptosis during malignant transformation, facilitating the development of a wide range of cancer types ${ }^{145}$

\section{Promoting apoptotic cell death for therapeutic benefit.}

Based on our understanding of apoptosis regulation in cancers, great effort across many academic and industry laboratories has been dedicated to the development of agents that can inhibit pro-survival protein function with an aim to promote apoptosis in cancer cells (see Box 1 for details).

The involvement of BCL-2 family proteins in several types of autoimmune disorders suggests that inhibiting pro-survival protein function may reverse the abnormal accumulation of cells that would typically be destined for deletion. BH3 mimetics may thus have therapeutic efficacy in these diseases and promising results have emerged from preclinical studies. For example, in the mouse model of SLE, treatment with BCL-2 inhibitor venetoclax reduced the numbers of peripheral B cells and dampened phenotypes associated with the disease ${ }^{146,147}$. Based on the success in mouse studies, clinical trials are now underway to evaluate venetoclax in patients diagnosed with SLE. This treatment seems to show good tolerability ${ }^{148}$ but therapeutic data are not yet available.

As highlighted above, infectious pathogens frequently suppress apoptosis in host cells as a part of their infectious strategy. Theoretically, inhibiting the pro-survival signalling in these situations would allow for apoptosis to proceed as intended and potentially could prevent expansion of infectious pathogens in the host. So far, BH3 mimetics have been shown to be effective during $L$. pneumophila infection. In this case, the bacterium blocks host cell protein synthesis causing a reduction in expression of high-turnover MCL1 and sensitizing cells to BCL- $\mathrm{X}_{\mathrm{L}}$ inhibition $^{149}$. Although using BH3 mimetics to target mammalian BCL-2 family proteins can be efficacious in certain contexts, developing agents that block the 
function of the pathogen-encoded counterparts would likely further widen the therapeutic index. A potential challenge here is the development of small molecules that inhibit the activity of pro-survival proteins expressed by the pathogen but not their mammalian counterparts and we need to learn more about how to target these pathogenic proteins.

\section{Excessive apoptosis in disease}

Similarly to insufficient apoptosis, the loss of cells due to inappropriate or excessive apoptosis may be deleterious. The most notable example includes the non-regenerative tissues, such as the brain, which are particularly susceptible to the loss of cells. Excessive apoptosis can also be caused by pathogens.

\section{Neuronal cell death in neurodegenerative diseases.}

Prominent neurodegenerative diseases including Alzheimer disease, amyotrophic lateral sclerosis (ALS), Parkinson disease and Huntington disease are all characterized by the accumulation of misfolded proteins ${ }^{150,151}$, which eventually disrupt the nervous system by aggregating and depositing within cells or the extracellular matrix, culminating in the dysfunction or loss of neurons ${ }^{5}$. Although apoptosis is important for perinatal brain development as discussed above, in adults the vast majority of cells in the nervous system are post-mitotic and profoundly resistant to apoptosis (apoptosis refractory) owing to insufficient expression of pre- and post-MOMP pro-apoptotic proteins ${ }^{46,152-154}$ (Fig. 2 and Fig. 3). Despite this, apoptosis-associated proteins may be upregulated during the pathogenesis of these diseases and, as discussed below, may represent a potential novel therapeutic target for neurodegeneration.

In Alzheimer disease, the accumulation of amyloid- $\beta$ [G] (A $\beta$ ) peptides and tau [G]containing neurofibrillary tangles [G] (NFTs) leads to the dysfunction and death of neurons, resulting in a progressive dementia that is eventually fatal ${ }^{5}$. Although the exact mechanisms by which neurons undergo cell death in response to the $A \beta$ peptides and tau NFTs is unclear, it has been shown that synthetic $\mathrm{A} \beta$ peptides can activate caspase 3 and induce apoptosis in cultured neurons ${ }^{155}$. Interestingly, several groups have reported that caspases may also directly cleave tau and drive formation of NFTs ${ }^{155}$, potentially linking A $\beta$ to tau NFT formation and to Alzheimer disease pathogenesis. Other studies have provided evidence that A $\beta$ kills neurons by first inducing membrane-associated oxidative stress, resulting in lipid peroxidation and the production of 4-hydroxynonenal [G] ${ }^{156}$ and ceramide [G] ${ }^{157}$, which activate the intrinsic mitochondria-dependent apoptosis pathway. Most pertinent to this Review, $A \beta$ has been reported to induce apoptosis by downregulating BCL-2 and upregulating $\mathrm{BAX}$ in addition to inducing oxidative stress and apoptotic cascades in synapses and dendrites ${ }^{158}$. However, it is important to note that in vitro cultures of primary neurons are typically derived from embryos or neonates and these cells are more sensitive to apoptotic cell death than adult neurons ${ }^{46}$ (see above), thus making generalization to human disease challenging.

Several mouse lines expressing human $\mathrm{A} \beta$ precursor (APP) show age-dependent accumulation of $A \beta$ in the hippocampus and cerebral cortex, decreased neurogenesis and increased neurodegeneration along with markers of apoptosis ${ }^{159}$. In support of the 
contribution of intrinsic apoptosis to the pathology of Alzheimer disease, it was shown that the expression of pro-apoptotic BAX and BAK is increased in hippocampal neurons in the majority of brains obtained from individuals affected by Alzheimer disease, along with changes in other BCL-2 family proteins ${ }^{4,160}$. Furthermore, the potential benefit of inhibiting mitochondrial apoptosis has been directly demonstrated through the use of a triple

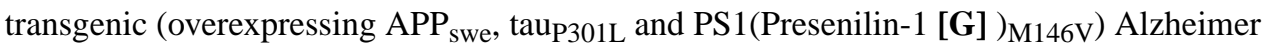
disease mouse model wherein overexpression of anti-apoptotic BCL-2 blocked activation of caspase 9 and caspase 3; in these conditions, the degree of caspase cleavage of tau was limited, the formation of plaques and NFTs was inhibited and memory retention was improved $^{161}$.

The pathological hallmark of Parkinson disease is progressive and selective dopaminergic neuronal degeneration in the substantia nigra pars compacta ( $\mathrm{SNpc}$ ), the brain region that controls motor activity ${ }^{162}$. Although the mechanisms underlying the selective loss of nigrostriatal dopaminergic neurons in this disease have not yet been elucidated, it has been shown that Parkinson disease is associated with mitochondrial dysfunction and several recent human post-mortem studies have suggested that dopaminergic neurons die by apoptosis $^{162}$. To date, at least three genes have been found to be associated with Parkinson disease; these genes encode: $a$-synuclein, parkin, and PTEN-induced kinase 1 (PINK1) ${ }^{162}$. Deletion of PINK1 in human and mouse neurons sensitizes them to apoptosis as evidenced by decreased overall viability and increased caspase 3 activation in response to the classical apoptosis-inducing pan-kinase inhibitor staurosporine ${ }^{163}$. Parkin deficiency, which is a prominent cause of familial Parkinson disease, may contribute to heightened apoptotic sensitivity of cultured cells of neural lineage ${ }^{164}$. Adding further evidence to the causative role of apoptosis in Parkinson disease, experimental mouse models of the disease have shown that $\mathrm{p} 53$-mediated upregulation of BAX is a necessary step in SNpc dopaminergic neuron apoptosis caused by mitochondrial dysfunction (inhibition of respiratory complex I) ${ }^{165}$.

ALS is a common motor neuron disease initiated by the loss of motor neurons in the brain and spinal cord ${ }^{164}$, which leads to muscle weakness, paralysis and ultimately to death due to respiratory failure. Several gene mutations have been identified that contribute to this disorder with more than $20 \%$ of familial ALS cases being linked to mutations in the gene encoding copper/zinc superoxide dismutase 1 (SOD1) ${ }^{166}$. Alterations in the expression of different BCL-2 family members have been described in the spinal cord of transgenic mice expressing mutant SOD1 and in humans affected with ALS ${ }^{164}$. Moreover, survival of SOD1 mutant mice is prolonged by the overexpression of BCL-2 ${ }^{164}$. Importantly, it has been shown that although BAX deletion only slightly increases the survival of SOD1 mutant mice, it strongly protects motor neurons against apoptosis and improves motor function by preventing neuronal loss and degeneration, slowing onset of ALS symptoms, including paralysis ${ }^{167}$.

Huntington disease is an inherited neurodegenerative disease characterized by chorea [G], personality changes, dementia and early death ${ }^{168}$, which results from the selective death and dysfunction of specific neuronal subpopulations within the central nervous system. The gene responsible for these effects encodes huntingtin, which contains a polymorphic stretch of 
repeated CAG trinucleotides, encoding a polyglutamine tract. Huntingtin gene in healthy people possesses less than 20 repeats and huntingtin with more than 35 repeats results in a higher probability of developing Huntington disease. In vitro models of Huntington disease show clear signs of apoptosis as indicated by neurite loss or destruction, chromatin condensation, nuclear pyknosis and fragmentation ${ }^{168}$. In support of the role of apoptotic cell death in neurodegeneration in Huntington disease, brains of individuals expressing mutant huntingtin reproducibly stain for apoptotic markers (TUNEL [G] -positivity, activation of caspases 1,3,6, and 8) and these effects can be inhibited in mice by co-expression of BCL-2, BCL- $\mathrm{X}_{\mathrm{L}}$ or caspase inhibitors ${ }^{169}$.

In summary, although these different neurodegenerative diseases are driven by highly diverse mechanisms, they broadly involve the loss of neurons, often through apoptosis, which then results in disease-associated phenotypes. In each case, direct and potent inhibitors of BAX and BAK would potentially be effective at preventing the loss of neurons and delaying disease progression and mortality. However, the degree to which these strategies would be effective therapeutically depends on whether the host would be better served by keeping a damaged or dysfunctional neural cells in place, or perhaps allowing them to die via apoptosis. This question can only be answered by assessing functional outcomes including, for example, motor function, cognition and long-term survival upon apoptosis inhibition. Although some evidence, as outlined above, indicates that blocking mitochondrial apoptosis can have therapeutic benefit in neurodegeneration, other studies have demonstrated mixed results ${ }^{170}$.

\section{Acute brain injuries.}

Cerebral ischaemia has traditionally been considered to induce an exclusively necrotic cell death in affected neural cells ${ }^{171}$. However, more recent work has demonstrated that although cells within the ischaemic core indeed die via necrosis, those within the penumbra [G] may remain metabolically active and die via apoptosis at a later time point, which exacerbates tissue loss and dysfunction ${ }^{172}$. Several reports connect BCL-2 family proteins directly to ischaemia-reperfusion injury in the brain, including evidence of BID cleavage (indicative of activation) following ischaemia in brain tissue and observations that loss of BID reduces the extent of infarcted brain tissue ${ }^{173}$. However, there is little data showing that inhibition of mitochondrial apoptosis may be effective at minimizing ischaemia-reperfusion-associated dysfunction in adult brain tissue ${ }^{174}$. Nevertheless, based on the increased expression of apoptosis-related genes in the developing brain, we propose that mitochondrial apoptosis is most involved in ischaemia-reperfusion injury in young humans (especially during the perinatal period and infancy) and not adults. As expected, BAX and downstream caspases are activated in a neonatal model of ischaeemia-reperfusion injury ${ }^{175}$.

Similar to cerebral ischaemia, there seems to be a greater role for mitochondrial apoptosis in neonatal traumatic brain injuries than in adults ${ }^{176,177}$. This would suggest that the apoptotically primed cells within the brain respond to certain injuries with pro-apoptotic signalling that can effectively activate BAX. It is thus likely that brains of young mammals would be hypersensitive to any types of damage or stress that induces apoptotic signalling due to their heightened BAX expression and apoptotic priming (Fig. 3). 


\section{Cell death induced by pathogens.}

In contrast to mechanisms inhibiting cell death in host cells upon infection mentioned above, which are only starting to emerge, it is well recognized that apoptosis has an important role in the deleterious effects of infection in humans. Here, we will describe two notable examples.

In Nobel prize-winning work, Helicobacter pylori was shown to be directly responsible for the development of gastritis and eventually peptic ulcers ${ }^{137}$, along with gastric lymphomas and adenocarcinomas. $H$. pylori contains several virulence factors; among these, vacuolating cytotoxin (VacA) has been shown to directly induce mitochondrial apoptosis in gastric epithelial cells and is thought to play a crucial role in the development of ulcers in the duodenum ${ }^{178}$. Mechanistically, VacA can induce receptor-like protein tyrosine phosphatase (RPTP $\beta$ ) to cause activation of BAX and BAK ${ }^{179}$. In addition, this toxin inhibits JAKSTAT3 signalling, causing downregulation of pro-survival proteins BCL-2 and BCL- $\mathrm{X}_{\mathrm{L}}$, leading to apoptosis ${ }^{180}$.

As another example, prolonged infection with the human immunodeficiency virus (HIV) causes acquired immunodeficiency syndrome (AIDS), owing to progressive loss of CD4+ T cells, which involves BCL-2 family proteins at several levels. First, HIV triggers apoptosis in T cells upon infection by producing HIV proteases that specifically cleave and inactivate BCL-2 (ref. ${ }^{181}$ ), thereby shifting the balance of pro-survival and pro-apoptotic proteins toward apoptosis. Furthermore, infected cells also secrete viral proteins such as gp120, Tat and Nef into the extracellular environment. Gp120 binds various receptors on T cells, which activate the extrinsic as well as the intrinsic apoptosis pathways in bystander (not necessarily infected) $\mathrm{T}$ cells ${ }^{182}$. Intrinsic apoptosis of bystander $\mathrm{T}$ cells is proposed to be driven by gp120-mediated upregulation of $\mathrm{BAX}^{183}$ along with concurrent downregulation of BCL-2 (ref. ${ }^{184}$ ).

It is important to note that pathogen-induced death of infected cells may also occur via necrosis - this is especially true of the lytic phase of infection, during which extensive bacterial or viral replication has been completed and when necrotic cell death facilitates the maximal spread of infectious material to additional host cells and, eventually, additional host organisms ${ }^{105,185}$.

\section{Inhibiting apoptotic cell death for therapeutic benefit.}

The strong evidence of apoptosis having a role in many diseases associated with abnormal cell loss has prompted efforts to drug this pathway for therapeutic benefit. However, the lack of potent and selective inhibitors of apoptosis, especially at the level of the BCL-2 family, has prevented more rigorous evaluation of the therapeutic potential in this space. Early studies tested the therapeutic efficacy of pan-caspase inhibitors such as Z-VAD-fmk that could block the key executioner caspases. Importantly, the use of these agents is expected to have limited clinical benefit for direct apoptosis inhibition because they work downstream of MOMP and cannot reverse the profound damage to mitochondrial function that is induced by BAX and BAK-mediated pore formation. Nevertheless, pharmacologic inhibition of caspases is able to reduce caspase activation in response to ischaemia and traumatic injuries 
in adult brain tissue and can provide a therapeutic effect, in particular when combined with antagonists of the N-Methyl-D-aspartate (NMDA) receptor, which reduce excitotoxicity [G] 186. It is possible that caspase inhibitors are acting via mechanisms outside of apoptosis prevention in these scenarios, such as the prevention of caspase-mediated cleavage of targets unrelated to apoptosis, as is the case for tau ${ }^{155}$. In addition, due to the involvement of caspases in key processes such as inflammation, these inhibitors may be blocking inflammatory pathways that have pathogenic roles such as neuroinflammation ${ }^{187}$. In neonates, several studies closely examined the use of caspase inhibitors for neuroprotection, reporting that they reduce caspase activation, TUNEL positivity as well as tissue damage ${ }^{188-190}$. Crucially, however, when functional outcomes were tested, the administration of these agents did not lead to improvement in post-injury motor or executive function $^{188}$, again suggesting that inhibiting caspases is not likely sufficient to completely block injury-associated dysfunction if the primary mechanism is mitochondrial apoptosis.

More recently, agents that directly inhibit the activity of BAX have been reported based on strong in vitro evidence of binding and cell death inhibition ${ }^{191}$ (Box 1). Excitingly, these agents can protect neurons from excitotoxic damage in vitro ${ }^{191}$ and from ischaemia injury in vivo ${ }^{192}$ but likely require further optimization prior to clinical testing. Regardless, the development of these and additional agents is expected to provide new opportunities to reverse the progression of diseases that are driven by excessive apoptosis.

\section{CONCLUSIONS AND PERSPECTIVE}

Accumulating evidence suggests that deregulated — increased or decreased — apoptosis is involved in the pathological depletion or accumulation of cells in many human disorders. There is an unclear understanding, however, of the molecular mechanisms that drive deregulation of apoptosis during the onset of these diseases and how the apoptotic pathway may be modulated for clinical benefit. Continued research in this space should seek to define the cellular and molecular targets for controlling apoptosis - keeping it in check or enhancing, according to the need - and to explore their potential for clinical translation. Of crucial importance in this space is the use of functional and physiological assessments of cellular survival as measurements of therapeutic efficacy of potential therapeutic agents instead of simply the preservation or elimination of cells. For example, a cardiomyocyte that doesn't activate caspases in response to ischaemia-reperfusion injury may appear to be alive by typical biochemical measurements, but may be functionally inert. In fact, the presence of a functionally inert and damaged cell may be more deleterious to the host than a cell that has committed itself to apoptotic cell death and, as a result, has been cleared via nonimmunogenic processes and perhaps even replaced. In addition, therapeutic efforts must consider our growing knowledge of the pivotal roles of apoptosis in maintaining organismal homeostasis and the dynamic nature of its regulation in different tissues at different ages the modulation of apoptosis pharmacologically is expected to have drastically different effects in young individuals versus adults ${ }^{46,85,153}$ and potentially in humans of advanced age (in which apoptotic potential might change, as exemplified by the changes in apoptotic susceptibility in the HSC niche and platelets) ${ }^{104}$. In addition, although the roles of BCL-2 family proteins in adult tissues have been studied and are thought to be established, the effects of cellular damage, stress or disease-associated factors are difficult to predict and 
have not been comprehensively characterized. Thus, it is likely that the function of some BCL-2 family proteins can only become apparent in specific physiological or pathological contexts. Furthermore, although our understanding of BCL-2 family regulation by cellautonomous processes is steadily improving, how interactions between cells and their microenvironment (including immune cells, vasculature, growth factors and nutrient availability) can affect apoptotic signalling is highly complex and may not be clear for quite some time.

Despite these challenges, research into how BCL-2 family proteins regulate and deregulate physiology is proceeding at a rapid pace and additional opportunities for clinical translation are constantly being identified. In cancer, where the modulation of apoptosis has clear and strong rationale, the biggest challenge is identifying which patients are most likely to benefit from treatment with $\mathrm{BH} 3$ mimetics, and how to combine them with existing therapies to maximize efficacy and limit toxicity. Since these agents have on-target toxicities (for example, thrombocytopenia due to BCL- $\mathrm{X}_{\mathrm{L}}$ inhibition), the clinical development of biomarker assays that can measure cancer cell dependence on specific pro-survival BCL-2 family proteins are needed. A strong fundamental understanding of BCL-2 family protein function has been built and methods for assigning therapies ${ }^{193,194}$, monitoring responses ${ }^{195}$ and predicting mechanisms of therapy resistance ${ }^{196-198}$ are all now possible. Putting the efforts of so many into practice are the recent approvals for the first ever use of BH3 mimetics for cancer therapy ${ }^{116}$, with many future successes in the modulation of BCL-2 family proteins for clinical benefit on the horizon (Box 1).

\section{Supplementary Material}

Refer to Web version on PubMed Central for supplementary material.

\section{Acknowledgements:}

The authors acknowledge the many researchers who contributed to our understanding of apoptosis and apologize that we could not cite all of the relevant research due to space restrictions. We thank Ben Croker, Gaurav Joshi, Adam Presser, Johan Spetz, Kaitlyn Webster and Tim Gershon for critical feedback and helpful discussions. We gratefully acknowledge funding from the Alex's Lemonade Stand Foundation for Childhood Cancers Young Investigator Award (K.S.), Andrew McDonough B+ Foundation Childhood Cancer Research Grant (K.S.), Harvard T.H. Chan School of Public Health Dean's Fund for Scientific Advancement (K.S.), Making Headway Foundation St. Baldrick's Research Grant (K.S) as well as NIH/NCI grant R00CA188679 (K.S.).

\section{Glossary:}

\section{Death receptor}

A subgroup of the tumour necrosis factor receptor (TNFR) superfamily that can activate the extrinsic apoptosis pathway via a conserved cytoplasmic signalling platform called the death domain. Prominent members of this family include Fas (also known as Apo-1 and CD95), TNF-R1, and TRAIL

\section{Cytochrome $c$}

an essential component of the electron transport chain within mitochondria, where it carries electrons. When released from mitochondria as a result of BAX/BAK activation, cytochrome 
$\mathrm{c}$ has a prominent role in controlling the commitment to apoptosis - it binds to APAF1 to form the apoptosome, which activates caspases

\section{Apoptosome}

a quaternary protein complex composed of cytoplasmic cytochrome c, APAF1 and dATP that recruits and activates the normally inactive pro-caspase 9 , which then activates effector caspases to prepare cell for phagocytosis

\section{SMAC (second mitochondria-derived activator of caspases; also known as DIABLO)}

a protein that is released from mitochondria during mitochondrial outer membrane permeabilization to bind and inactivate XIAP to promote caspase activation

\section{XIAP ( X-linked inhibitor of apoptosis protein)}

a member of the inhibitor of apoptosis family of proteins (IAP) that can prevent caspase activation. XIAP binds and inactivates caspases 3, 7 and 9 via its BIR2 and BIR3 domains

\section{cGAS-STING}

Cyclic guanosine monophosphate (GMP)-adenosine monophosphate (AMP) synthase (cGAS) is a DNA-sensing molecule that activates innate immune responses through production of the second messenger cyclic GMP-AMP (cGAMP), which then binds and activates the adaptor protein stimulator of IFN gene (STING). Importantly, cGAS is activated by double-stranded DNA that can be foreign or self

\section{DAMPs (damage-associated molecular pattern molecules)}

signals that initiate and perpetuate immune activation in response to tissue damage, trauma, or ischaemia regardless of whether pathogens are present at site of injury

\section{ER stress}

a response of the endoplasmic reticulum (ER) to aberrations of protein folding (and other stresses), which is aimed at clearing unfolded proteins and restoring ER homeostasis. In cases when this cannot be accomplished, cellular functions degenerate and often result in apoptosis

\section{Activation-induced cell death}

A programmed cell death process initiated in immune cells (especially $\mathrm{T}$ cells) by repeated stimulation of their T-cell receptor that helps to maintain peripheral immune tolerance

\section{Ischaemia-reperfusion injury}

a type of tissue damage resulting from initial ischaemia or hypoxia, followed by reoxygenation, as seen in myocardial infarction, ischaemic stroke and other traumas

\section{Sertoli cells}

elongated cells of the seminiferous tubules within the testis to which spermatids attach during spermatogenesis for support and nourishment

\section{Double-negative T cells}

$\mathrm{T}$ cells expressing the $\mathrm{T}$ cell receptor but lacking CD4, CD8 or NK cell markers 


\section{Amyloid- $\beta$ (A $\beta$ )}

a peptide produced through the proteolytic cleavage of a transmembrane protein, amyloid precursor protein (APP), by $\beta$ - and $\gamma$-secretases. Accumulation of A $\beta$ in the brain is thought to be an early event in the pathogenesis of Alzheimer disease

Tau

the major microtubule associated protein (MAP) of a normal post-mitotic and mature neuron. Tau has six molecular isoforms that are generated by alternative splicing and is thought to promote the assembly of tubulin into microtubules. In Alzheimer disease and other 'tauopathies', tau is hyperphosphorylated and aggregates into neurofibrillary tangles to impair neuronal function

\section{Neurofibrillary tangles (NFTs)}

Aggregates of hyperphosphorylated tau proteins within neurons that cause dysfunction

\section{4-Hydroxynonenal (4-HNE)}

a product of lipid peroxidation that can induce apoptosis

\section{Ceramide}

A lipid that acts as a second messenger in activating apoptosis within the sphingomyelin pathway, which is initiated by the hydrolysis of the plasma membrane phospholipid sphingomyelin

\section{Presenilin-1}

The catalytic subunit of $\gamma$-secretase, which is a protease that cleaves a variety of type 1 transmembrane proteins, most notably amyloid precursor protein. Mutations in the PSEN1 gene encoding presenilin-1 are the most common cause of familial Alzheimer disease

\section{Chorea}

a movement disorder that causes involuntary, unpredictable body movements

\section{TUNEL (terminal deoxynucleotidyl transferase dUTP nick end labelling)}

an assay that detects fragmented DNA, which is one of the hallmarks of apoptotic cell death

\section{Penumbra}

in medicine, the area surrounding the focal point of an ischaemic event

\section{Excitotoxicity}

a process, whereby cells in the nervous system are killed by excessive neurotransmitter stimulation

\section{Cell-cycle checkpoint violation}

failure of a cell to stop at specific checkpoints in the cell cycle when it would normally examine internal and external cues to determine whether to advance with cell division

\section{REFERENCES}

1. Rathmell JC \& Thompson CB Pathways of apoptosis in lymphocyte development, homeostasis, and disease. Cell 109, S97-107 (2002). [PubMed: 11983156] 
2. Sedger LM et al. Extreme lymphoproliferative disease and fatal autoimmune thrombocytopenia in FasL and TRAIL double-deficient mice. Blood 115, 3258-68 (2010). [PubMed: 20185587]

3. Lamhamedi-Cherradi SE, Zheng SJ, Maguschak KA, Peschon J \& Chen YH Defective thymocyte apoptosis and accelerated autoimmune diseases in TRAIL-/- mice. Nat. Immunol 4, 255-260 (2003). [PubMed: 12577054]

4. Su JH, Deng G \& Cotman CW Bax Protein Expression Is Increased in Alzheimer's Brain: Correlations with DNA Damage, Bcl-2 Expression, and Brain Pathology. J. Neuropathol. Exp. Neurol 56, 86-93 (1997). [PubMed: 8990132]

5. Lu T et al. REST and stress resistance in ageing and Alzheimer's disease. Nature 507, 448-54 (2014). [PubMed: 24670762]

6. Paulino AC, Constine LS, Rubin P \& Williams JP Normal Tissue Development, Homeostasis, Senescence, and the Sensitivity to Radiation Injury Across the Age Spectrum. Semin. Radiat. Oncol 20, 12-20 (2010). [PubMed: 19959027]

7. Nakaya K et al. Sensitivity to radiation-induced apoptosis and neuron loss declines rapidly in the postnatal mouse neocortex. Int. J. Radiat. Biol 81, 545-54 (2005). [PubMed: 16263658]

8. Lipshultz SE, Cochran TR, Franco VI \& Miller TL Treatment-related cardiotoxicity in survivors of childhood cancer. Nat. Rev. Clin. Oncol 10, 697-710 (2013). [PubMed: 24165948]

9. Honarpour N, Gilbert SL, Lahn BT, Wang X \& Herz J Apaf-1 deficiency and neural tube closure defects are found in fog mice. Proc. Natl. Acad. Sci. U. S. A 98, 9683-7 (2001). [PubMed: 11504943]

10. Ke FFS et al. Embryogenesis and Adult Life in the Absence of Intrinsic Apoptosis Effectors BAX, BAK, and BOK. Cell 173, 1217-1230.e17 (2018). [PubMed: 29775594] This study highlights the importance of apoptosis in mammalian development but also shows that a viable mouse can emerge without intrinsic apoptosis

11. Knudson CM, Tung KS, Tourtellotte WG, Brown G a \& Korsmeyer, S. J. Bax-deficient mice with lymphoid hyperplasia and male germ cell death. Science 270, 96-9 (1995). [PubMed: 7569956]

12. Eischen CM, Roussel MF, Korsmeyer SJ \& Cleveland JL Bax loss impairs Myc-induced apoptosis and circumvents the selection of p53 mutations during Myc-mediated lymphomagenesis. Cell. Biol 21, 7653-62 (2001).

13. Luke JJ, Van De Wetering CI \& Knudson CM Lymphoma development in Bax transgenic mice is inhibited by Bcl-2 and associated with chromosomal instability. Cell Death Differ. 10, 740-8 (2003). [PubMed: 12761582]

14. Los M et al. Requirement of an ICE/CED-3 protease for Fas/APO-1-mediated apoptosis. Nature 375, 81-83 (1995). [PubMed: 7536901]

15. Miura M, Zhu H, Rotello R, Hartwieg EA \& Yuan J Induction of apoptosis in fibroblasts by IL-1Bconverting enzyme, a mammalian homolog of the c.elegans cell death gene ced-3. Cell 75, 653660 (1993). [PubMed: 8242741]

16. Ramage $\mathrm{P}$ et al. Expression, refolding, and autocatalytic proteolytic processing of the interleukin-1??-converting enzyme precursor. J. Biol. Chem 270, 9378-9383 (1995). [PubMed: 7721861]

17. Sabbatini P, Han J, Chiou SK, Nicholson DW \& White E Interleukin 1 beta converting enzyme-like proteases are essential for p53-mediated transcriptionally dependent apoptosis. Cell Growth Differ 8, 643-653 (1997). [PubMed: 9185998]

18. Galluzzi L et al. Molecular mechanisms of cell death: recommendations of the Nomenclature Committee on Cell Death 2018. Cell Death Differ. (2018). doi:10.1038/s41418-017-0012-4.This is a comprehensive overview and comparison of cell death modalities.

19. Cotter TG Apoptosis and cancer: the genesis of a research field therapy. Nat. Rev. Cancer 9, 501507 (2009). [PubMed: 19550425]

20. Fuchs Y \& Steller H Programmed cell death in animal development and disease. Cell 147, 742-58 (2011). [PubMed: 22078876]

21. Letai A et al. Distinct BH3 domains either sensitize or activate mitochondrial apoptosis, serving as prototype cancer therapeutics. Cancer Cell 2, 183-92 (2002). [PubMed: 12242151] 
22. Maas $\mathrm{C}$ et al. Smac/DIABLO release from mitochondria and XIAP inhibition are essential to limit clonogenicity of Type I tumor cells after TRAIL receptor stimulation. Cell Death Differ. 17, 161323 (2010). [PubMed: 20395960]

23. Brunet CL et al. Commitment to cell death measured by loss of clonogenicity is separable from the appearance of apoptotic markers. Cell Death Differ. 5, 107-115 (1998). [PubMed: 10200451]

24. Marsden VS et al. Apoptosis initiated by Bcl-2- regulated caspase activation independently of the cytochrome c / Apaf-1 / caspase-9 apoptosome. Nature 419, 6-9 (2002).

25. Tait SWG \& Green DR Mitochondrial regulation of cell death. Cold Spring Harb. Perspect. Biol 5, (2013).

26. Tait SWG et al. Resistance to Caspase-Independent Cell Death Requires Persistence of Intact Mitochondria. Dev. Cell 18, 802-813 (2010). [PubMed: 20493813]

27. Ichim $\mathrm{G}$ et al. Limited Mitochondrial Permeabilization Causes DNA Damage and Genomic Instability in the Absence of Cell Death. Mol. Cell 57, 860-872 (2015). [PubMed: 25702873]

28. Liu X et al. Caspase-3 Promotes Genetic Instability and Carcinogenesis. Mol. Cell 58, 1-13 (2015). [PubMed: 25839429]

29. White MJ et al. Apoptotic caspases suppress mtDNA-induced STING-mediated type i IFN production. Cell 159, 1549-1562 (2014). [PubMed: 25525874]

30. McArthur K et al. BAK/BAX macropores facilitate mitochondrial herniation and mtDNA efflux during apoptosis. Science (80-. ). 359, (2018). This paper describe the role of BAX/BAK pores in the transfer of mitochondrial DNA into the cytoplasm where it can activate pro-inflammatory responses.

31. Riley $\mathbf{J}$ et al. Activated BAX/BAK enable mitochondrial inner membrane permeabilisation and mtDNA release during cell death. bioRxiv 272104 (2018). doi:10.1101/272104.This paper describe the role of BAX/BAK pores in the transfer of mitochondrial DNA into the cytoplasm where it can activate pro-inflammatory responses.

32. Vanpouille-Box C, Demaria S, Formenti SC \& Galluzzi L Cytosolic DNA Sensing in Organismal Tumor Control. Cancer Cell (2018). doi:10.1016/j.ccell.2018.05.013

33. West AP \& Shadel GS Mitochondrial DNA in innate immune responses and inflammatory pathology. Nature Reviews Immunology 17, 363-375 (2017).

34. Czabotar PE, Lessene G, Strasser A \& Adams JM Control of apoptosis by the BCL-2 protein family: implications for physiology and therapy. Nat. Rev. Mol. Cell Biol 15, 49-63 (2013).

35. Czabotar PE et al. Bax crystal structures reveal how BH3 domains activate Bax and nucleate its oligomerization to induce apoptosis. Cell 152, 519-531 (2013). [PubMed: 23374347] This study demonstrates that $\mathrm{BAX}$ is activated by a pro-apoptotic peptide to unify competing models of activation.

36. Kim $\mathrm{H}$ et al. Hierarchical regulation of mitochondrion-dependent apoptosis by BCL-2 subfamilies. Nat. Cell Biol 8, 1348-58 (2006). [PubMed: 17115033]

37. Leshchiner ES, Braun CR, Bird GH \& Walensky LD Direct activation of full-length proapoptotic BAK. Proc. Natl. Acad. Sci. U. S. A 1-10 (2013). doi:10.1073/pnas.1214313110

38. Wei M et al. tBID, a membrane-targeted death ligand, oligomerizes BAK to release cytochrome c. Genes ... 2060-2071 (2000). doi:10.1101/gad.14.16.2060

39. Dai H, Pang Y-P, Ramirez-Alvarado M \& Kaufmann SH Evaluation of the BH3-Only Protein Puma as a Direct Bak Activator. J. Biol. Chem 0-25 (2013). doi:10.1074/jbc.M113.505701

40. Glab JA, Mbogo GW \& Puthalakath H BH3-Only Proteins in Health and Disease. International Review of Cell and Molecular Biology 328, (Elsevier Inc., 2017).

41. Sarosiek KA et al. BID preferentially activates BAK while BIM preferentially activates BAX, affecting chemotherapy response. Mol. Cell 51, 751-765 (2013). [PubMed: 24074954]

42. Kuwana $\mathrm{T}$ et al. BH3 domains of BH3-only proteins differentially regulate Bax-mediated mitochondrial membrane permeabilization both directly and indirectly. Mol. Cell 17, 525-35 (2005). [PubMed: 15721256]

43. Uren RT et al. Mitochondrial permeabilization relies on BH3 ligands engaging multiple prosurvival Bcl-2 relatives, not Bak. J. Cell Biol 177, 277-287 (2007). [PubMed: 17452531] 
44. Certo $\mathrm{M}$ et al. Mitochondria primed by death signals determine cellular addiction to antiapoptotic BCL-2 family members. Cancer Cell 9, 351-65 (2006). [PubMed: 16697956]

45. Opferman JT et al. Development and maintenance of B and T lymphocytes requires antiapoptotic MCL-1. Nature 426, 570-574 (2003). [PubMed: 14654843]

46. Sarosiek KA et al. Developmental Regulation of Mitochondrial Apoptosis by c-Myc Governs Ageand Tissue-Specific Sensitivity to Cancer Therapeutics. Cancer Cell 31, 142-156 (2017). [PubMed: 28017613] This paper provides a demonstration that apoptotic priming, which is dynamically and differently regulated across healthy tissues, is important for cellular sensitivity to damage or stress

47. Moldoveanu T et al. BID-induced structural changes in BAK promote apoptosis. Nat. Struct. Mol. Biol (2013). doi:10.1038/nsmb.2563

48. Neill KLO, Huang K, Zhang J, Chen Y \& Luo X Inactivation of prosurvival Bcl-2 proteins activates Bax / Bak through the outer mitochondrial membrane. Genes \{\&\} Dev. 30, 1-16 (2016). [PubMed: 26728553]

49. Eriksson D \& Stigbrand T Radiation-induced cell death mechanisms. Tumour Biol 31, 363-372 (2010). [PubMed: 20490962]

50. Kaufmann SH \& Earnshaw WC Induction of apoptosis by cancer chemotherapy. Exp. Cell Res 256, 42-9 (2000). [PubMed: 10739650]

51. Corazzari M, Gagliardi M, Fimia GM \& Piacentini M Endoplasmic Reticulum Stress, Unfolded Protein Response, and Cancer Cell Fate. Front. Oncol 7, 1-11 (2017). [PubMed: 28168163]

52. Sarosiek KA et al. Efficacy of bortezomib in a direct xenograft model of primary effusion lymphoma. Proc. Natl. Acad. Sci. U. S. A 107, 13069-74 (2010). [PubMed: 20615981]

53. Panduri V, Weitzman SA, Chandel NS \& Kamp DW Mitochondrial-derived free radicals mediate asbestos-induced alveolar epithelial cell apoptosis. Am. J. Physiol. Cell. Mol. Physiol 286, L1220L1227 (2004).

54. Wong K-K, Engelman JA \& Cantley LC Targeting the PI3K signaling pathway in cancer. Curr. Opin. Genet. Dev 20, 87-90 (2010). [PubMed: 20006486]

55. Sarosiek KAK et al. Novel IL-21 signaling pathway up-regulates c-Myc and induces apoptosis of diffuse large B-cell lymphomas. Blood 115, 570-580 (2010). [PubMed: 19965678]

56. Wensveen FM et al. Apoptosis threshold set by noxa and Mcl-1 after T cell activation regulates competitive selection of high-affinity clones. Immunity 32, 754-765 (2010). [PubMed: 20620942]

57. Murphy DJ et al. Distinct thresholds govern Myc's biological output in vivo. Cancer Cell 14, 44757 (2008). [PubMed: 19061836]

58. Phesse TJ et al. Endogenous c-Myc is essential for p53-induced apoptosis in response to DNA damage in vivo. Cell Death Differ. 44, 956-66 (2014).

59. Garrison SP et al. Selection against PUMA gene expression in Myc-driven B-cell lymphomagenesis. Mol. Cell. Biol 28, 5391-5402 (2008). [PubMed: 18573879]

60. Evan G, Wyllie A, Gilbert C \& Littlewood T Induction of apoptosis in fibroblasts by c-myc protein. Cell 69, 119-128 (1992). [PubMed: 1555236]

61. Soucie EL et al. Myc potentiates apoptosis by stimulating Bax activity at the mitochondria. Mol. Cell. Biol 21, 4725-4736 (2001). [PubMed: 11416148]

62. Farlie PG, Dringen R, Rees SM, Kannourakis G \& Bernard O bcl-2 transgene expression can protect neurons against developmental and induced cell death. Proc. Natl. Acad. Sci. U. S. A 92, 4397-401 (1995). [PubMed: 7753817]

63. Mercille S \& Massie B Induction of apoptosis in nutrient-deprived cultures of hybridoma and myeloma cells. Biotechnol. Bioeng 44, 1140-1154 (1994). [PubMed: 18623032]

64. Wiederschain D, Kawai H, Shilatifard A \& Yuan Z-M Multiple mixed lineage leukemia (MLL) fusion proteins suppress p53-mediated response to DNA damage. J. Biol. Chem 280, 24315-21 (2005). [PubMed: 15851483]

65. de Polo A et al. AXL receptor signalling suppresses p53 in melanoma through stabilization of the MDMX-MDM2 complex. J. Mol. Cell Biol 9, 154-165 (2017). [PubMed: 27927748] 
66. Deng J et al. Proapoptotic BH3-only BCL-2 family protein BIM connects death signaling from epidermal growth factor receptor inhibition to the mitochondrion. Cancer Res. 67, 11867-75 (2007). [PubMed: 18089817]

67. Hata AN et al. Failure to induce apoptosis via BCL-2 family proteins underlies lack of efficacy of combined MEK and PI3K inhibitors for KRAS-mutant lung cancers. Cancer Res. 74, 3146-3156 (2014). [PubMed: 24675361]

68. Winter PS et al. RAS signaling promotes resistance to JAK inhibitors by suppressing BADmediated apoptosis. Sci. Signal 7, 1-12 (2014).

69. Lei K \& Davis RJ JNK phosphorylation of Bim-related members of the Bcl2 family induces Baxdependent apoptosis. Proc. Natl. Acad. Sci 100, 2432-2437 (2003). [PubMed: 12591950]

70. Putcha GV et al. JNK-mediated BIM phosphorylation potentiates BAX-dependent apoptosis. Neuron 38, 899-914 (2003). [PubMed: 12818176]

71. Wong WW-L \& Puthalakath H Bcl-2 family proteins: The sentinels of the mitochondrial apoptosis pathway. IUBMB Life 60, 390-397 (2008). [PubMed: 18425793]

72. Ni Chonghaile $\mathrm{T}$ et al. Pretreatment mitochondrial priming correlates with clinical response to cytotoxic chemotherapy. Science 334, 1129-33 (2011). [PubMed: 22033517]

73. Sarosiek KA, Ni Chonghaile T \& Letai A Mitochondria: gatekeepers of response to chemotherapy. Trends Cell Biol. 23, 1-8 (2013). [PubMed: 22980035]

74. Sarosiek KA \& Letai A Directly targeting the mitochondrial pathway of apoptosis for cancer therapy with BH3 mimetics: recent successes, current challenges and future promise. FEBS J. n/an/a (2016). doi:10.1111/febs.13714

75. Ryan J \& Letai A BH3 profiling in whole cells by fluorimeter or FACS. Methods (2013). doi:10.1016/j.ymeth.2013.04.006

76. Opferman JT \& Korsmeyer SJ Apoptosis in the development and maintenance of the immune system. Nat. Immunol 4, 410-5 (2003). [PubMed: 12719730]

77. Madden SD, Donovan M \& Cotter TG Key apoptosis regulating proteins are down-regulated during postnatal tissue development. Int. J. Dev. Biol 51, 415-23 (2007). [PubMed: 17616931]

78. Lindsten $\mathrm{T}$ et al. The combined functions of proapoptotic Bcl-2 family members bak and bax are essential for normal development of multiple tissues. Mol. Cell 6, 1389-99 (2000). [PubMed: 11163212]

79. Honarpour N et al. Adult Apaf-1-deficient mice exhibit male infertility. Dev. Biol 218, 248-258 (2000). [PubMed: 10656767]

80. Arakawa S et al. Role of Atg5-dependent cell death in the embryonic development of Bax/Bak double-knockout mice. Cell Death Differ. 24, 1598-1608 (2017). [PubMed: 28574506]

81. Garcia I et al. Bax deficiency prolongs cerebellar neurogenesis, accelerates medulloblastoma formation and paradoxically increases both malignancy and differentiation. Oncogene 32, 2304-14 (2013). [PubMed: 22710714]

82. Southwell DG et al. Intrinsically determined cell death of developing cortical interneurons. Nature 1-7 (2012). doi:10.1038/nature11523

83. Deckwerth TL et al. BAX is required for neuronal death after trophic factor deprivation and during development. Neuron 17, 401-11 (1996). [PubMed: 8816704]

84. Merchant TE, Pollack IF \& Loeffler JS Brain tumors across the age spectrum: biology, therapy, and late effects. Semin. Radiat. Oncol 20, 58-66 (2010). [PubMed: 19959032]

85. Crowther AJ et al. Tonic activation of Bax primes neural progenitors for rapid apoptosis through a mechanism preserved in medulloblastoma. J. Neurosci 33, 18098-108 (2013). [PubMed: 24227720]

86. Lidsky TI \& Schneider JS Lead neurotoxicity in children: basic mechanisms and clinical correlates. Brain 126, 5-19 (2003). [PubMed: 12477693]

87. Grandjean P \& Landrigan P Developmental neurotoxicity of industrial chemicals. Lancet 368 , 2167-2178 (2006). [PubMed: 17174709]

88. Andropoulos DB Effect of anesthesia on the developing brain: Infant and fetus. Fetal Diagn. Ther 43, 1-11 (2018). [PubMed: 28586779] 
89. Heine VM \& Rowitch DH Hedgehog signaling has a protective effect in glucocorticoid-induced mouse neonatal brain injury through an 11ßHSD2-dependent mechanism. J. Clin. Invest 119, 26777 (2009). [PubMed: 19164857]

90. Thornton C et al. Cell Death in the Developing Brain after Hypoxia-Ischemia. Front. Cell. Neurosci 11, 248 (2017). [PubMed: 28878624]

91. Biddle KR, McCabe A \& Bliss LS Narrative skills following traumatic brain injury in children and adults. J. Commun. Disord 29, 447-68-9 (1996).

92. Motoyama $\mathrm{N}$ et al. Massive cell death of immature hematopoietic cells and neurons in Bcl-Xdeficient mice. Science 267, 1506-10 (1995). [PubMed: 7878471]

93. Mitchell $\mathrm{KO}$ et al. Bax is a transcriptional target and mediator of c-Myc-induced apoptosis. Cancer Res. 60, 6318-6325 (2000). [PubMed: 11103792]

94. Strasser A, Harris AW \& Cory S bcl-2 transgene inhibits T cell death and perturbs thymic selfcensorship. Cell 67, 889-99 (1991). [PubMed: 1959134]

95. Okamoto $\mathrm{T}$ et al. Enhanced stability of $\mathrm{Mcl} 1$, a prosurvival $\mathrm{Bcl} 2$ relative, blunts stress-induced apoptosis, causes male sterility, and promotes tumorigenesis. Proc. Natl. Acad. Sci 111, 261-266 (2014). [PubMed: 24363325]

96. Shaha C, Tripathi R \& Prasad Mishra D Male germ cell apoptosis: Regulation and biology. Philos. Trans. R. Soc. B Biol. Sci 365, 1501-1515 (2010).

97. Rodriguez I, Araki K, Khatib K, Martinou JC \& Vassalli P Mouse vaginal opening is an apoptosisdependent process which can be prevented by the overexpression of Bcl2. Dev. Biol 184, 115-121 (1997). [PubMed: 9142988]

98. Rinkenberger JL, Horning S, Klocke B, Roth K \& Korsmeyer SJ Mcl-1 deficiency results in periimplantation embryonic lethality. Genes Dev. 14, 23-7 (2000). [PubMed: 10640272]

99. Escudero S et al. Dynamic Regulation of Long-Chain Fatty Acid Oxidation by a Noncanonical Interaction between the MCL-1 BH3 Helix and VLCAD. Mol. Cell 69, 729-743.e7 (2018). [PubMed: 29499131]

100. Perciavalle RM et al. Anti-apoptotic MCL-1 localizes to the mitochondrial matrix and couples mitochondrial fusion to respiration. Nat. Cell Biol 14, 1-11 (2012).

101. Pillay $\mathrm{J}$ et al. In vivo labeling with $2 \mathrm{H} 2 \mathrm{O}$ reveals a human neutrophil lifespan of 5.4 days. Blood 116, 625-7 (2010). [PubMed: 20410504]

102. Luedde T, Kaplowitz N \& Schwabe RF Cell Death and Cell Death Responses in Liver Disease: Mechanisms and Clinical Relevance. Gastroenterology 147, 765-783.e4 (2014). [PubMed: 25046161]

103. Pilzecker B et al. DNA damage tolerance in hematopoietic stem and progenitor cells in mice. Proc. Natl. Acad. Sci 114, 201706508 (2017).

104. Gutierrez-Martinez P et al. Diminished apoptotic priming and ATM signalling confer a survival advantage onto aged haematopoietic stem cells in response to DNA damage. Nat. Cell Biol 20, 413-421 (2018). [PubMed: 29531308]

105. Mason KD et al. Programmed Anuclear Cell Death Delimits Platelet Life Span. Cell 128, 11731186 (2007). [PubMed: 17382885]

106. Vlahovic $\mathrm{G}$ et al. A phase I safety and pharmacokinetic study of ABT-263 in combination with carboplatin/paclitaxel in the treatment of patients with solid tumors. Invest. New Drugs 32, 976984 (2014). [PubMed: 24894650]

107. Opferman JT \& Kothari A Anti-apoptotic BCL-2 family members in development. Cell Death Differ. 25, 37-45 (2018). [PubMed: 29099482]

108. Spetz J, Presser AG \& Sarosiek KA T Cells and Regulated Cell Death: Kill or Be Killed International Review of Cell and Molecular Biology 342, (Elsevier Ltd, 2018).

109. Zhao DY, Jacobs KM, Hallahan DE \& Thotala D Silencing Egr1 Attenuates Radiation-Induced Apoptosis in Normal Tissues while Killing Cancer Cells and Delaying Tumor Growth. Mol. Cancer Ther 14, (2015).

110. Spetz J, Moslehi J \& Sarosiek K Radiation-Induced Cardiovascular Toxicity: Mechanisms, Prevention, and Treatment. Curr. Treat. Options Cardiovasc. Med 20, (2018). 
111. Schuler F et al. The BH3-only protein BIM contributes to late-stage involution in the mouse mammary gland. Cell Death Differ. 23, 41-51 (2016). [PubMed: 26045049]

112. Bergmann A \& Steller H Apoptosis, stem cells, and tissue regeneration. Sci. Signal 3, re8 (2010). [PubMed: 20978240]

113. Wang K Molecular mechanisms of hepatic apoptosis. Cell Death Dis. 5, e996 (2014). [PubMed: 24434519]

114. Bakhshi A et al. Cloning the chromosomal breakpoint of $t(14 ; 18)$ human lymphomas: clustering around Jhon chromosome 14 and near a transcriptional unit on 18. Cell 41, 899-906 (1985). [PubMed: 3924412]

115. Tang HL et al. Cell survival, DNA damage, and oncogenic transformation after a transient and reversible apoptotic response. Mol Biol Cell 23, 2240-2252 (2012). [PubMed: 22535522]

116. Reed JC Bcl-2 on the brink of breakthroughs in cancer treatment. Cell Death Differ. 25, 3-6 (2018). [PubMed: 29227986]

117. Whitfield JR, Beaulieu M-E \& Soucek L Strategies to Inhibit Myc and Their Clinical Applicability. Front. Cell Dev. Biol 5, 1-13 (2017). [PubMed: 28184371]

118. Hanahan D \& Weinberg R The hallmarks of cancer. Cell 100, 57-70 (2000). [PubMed: 10647931]

119. Strasser A, Harris AW, Bath ML \& Cory S Novel primitive lymphoid tumours induced in transgenic mice by cooperation between myc and bcl-2. Nature 348, 331-333 (1990). [PubMed: 2250704]

120. Lopez J \& Tait SWG Mitochondrial apoptosis: Killing cancer using the enemy within. Br. J. Cancer 112, 957-962 (2015). [PubMed: 25742467]

121. Birkinshaw RW \& Czabotar PE The BCL-2 family of proteins and mitochondrial outer membrane permeabilisation. Semin. Cell Dev. Biol 72, 152-162 (2017). [PubMed: 28396106]

122. Leverson JD et al. Found in Translation: How Preclinical Research Is Guiding the Clinical Development of the BCL2-Selective Inhibitor Venetoclax. Cancer Discov. (2017). doi:10.1158/2159-8290.CD-17-0797

123. Green DR Bench to Bedside A BH3 Mimetic for Killing Cancer Cells. Cell 165, 1560 (2016). [PubMed: 27315468]

124. Miquel C et al. Role of bax Mutations in Apoptosis in Colorectal Cancers With Microsatellite Instability. Am. J. Clin. Pathol 123, 562-570 (2005). [PubMed: 15743744]

125. Gardai SJ et al. Phosphorylation of Bax ser184 by Akt regulates its activity and apoptosis in neutrophils. J. Biol. Chem 279, 21085-21095 (2004). [PubMed: 14766748]

126. Kutuk O \& Letai A Regulation of Bcl-2 family proteins by posttranslational modifications. Curr. Mol. Med 8, 102-18 (2008). [PubMed: 18336291]

127. Siegel RL, Miller KD \& Jemal A Cancer Statistics, 2017. CA Cancer J Clin 67, 7-30 (2017). [PubMed: 28055103]

128. Huber HJ, McKiernan RG \& Prehn JHM Harnessing system models of cell death signalling for cytotoxic chemotherapy: towards personalised medicine approaches? J. Mol. Med. (Berl). (2014). doi:10.1007/s00109-014-1126-5

129. Mitchison TJ The proliferation rate paradox in antimitotic chemotherapy. Mol. Biol. Cell 23, 1-6 (2012). [PubMed: 22210845] This paper provides a balanced discussion on proliferation rate of cancer cells and their sensitivity to chemotherapy.

130. Sack LM et al. Profound Tissue Specificity in Proliferation Control Underlies Cancer Drivers and Aneuploidy Patterns. Cell 0, 1-16 (2018).

131. Watanabe-Fukunaga R, Brannan C, Nature, N. C.- \& 1992, U. Lymphoproliferation disorder in mice explained by defects in Fas antigen that mediates ap0ptosis. nature.com 192

132. Bouillet $\mathrm{P}$ et al. Proapoptotic Bcl-2 Relative Bim Required for Certain Apoptotic Responses, Leukocyte Homeostasis, and to Preclude Autoimmunity. Science (80-. ). 286, 1735-1738 (1999).

133. Strasser A et al. Enforced BCL2 expression in B-lymphoid cells prolongs antibody responses and elicits autoimmune disease. Proc. Natl. Acad. Sci 88, 8661-8665 (1991). [PubMed: 1924327]

134. Ina K et al. Resistance of Crohn's disease T cells to multiple apoptotic signals is associated with a Bcl-2/Bax mucosal imbalance. J. Immunol 163, 1081-90 (1999). [PubMed: 10395708] 
135. Parandhaman DK \& Narayanan S Cell death paradigms in the pathogenesis of Mycobacterium tuberculosis infection. Front. Cell. Infect. Microbiol 4, 31 (2014). [PubMed: 24634891]

136. Zhou X, Jiang W, Liu Z, Liu S \& Liang X Virus Infection and Death Receptor-Mediated Apoptosis. Viruses 9, 316 (2017).

137. Sly LM, Hingley-Wilson SM, Reiner NE \& McMaster WR Survival of Mycobacterium tuberculosis in host macrophages involves resistance to apoptosis dependent upon induction of antiapoptotic Bcl-2 family member Mcl-1. J. Immunol 170, 430-7 (2003). [PubMed: 12496428]

138. Banga $\mathrm{S}$ et al. Legionella pneumophila inhibits macrophage apoptosis by targeting pro-death members of the Bcl2 protein family. Proc. Natl. Acad. Sci 104, 5121-5126 (2007). [PubMed: 17360363]

139. Pauleau A-L et al. Structure-function analysis of the interaction between Bax and the cytomegalovirus-encoded protein vMIA. Oncogene 26, 7067-7080 (2007). [PubMed: 17496930]

140. Desbien AL, Kappler JW \& Marrack P The Epstein-Barr virus Bcl-2 homolog, BHRF1, blocks apoptosis by binding to a limited amount of Bim. Proc. Natl. Acad. Sci 106, (2009).

141. Flanagan AM \& Letai A BH3 domains define selective inhibitory interactions with BHRF-1 and KSHV BCL-2. Cell Death Differ. 15, 580-8 (2008). [PubMed: 18084238]

142. Rowe $\mathrm{M}$ et al. Upregulation of bcl-2 by the Epstein-Barr virus latent membrane protein LMP1: a B-cell-specific response that is delayed relative to NF-kappa B activation and to induction of cell surface markers. J. Virol 68, 5602-5612 (1994). [PubMed: 7520093]

143. Wang S, Rowe M \& Lundgren E Expression of the Epstein Barr virus transforming protein LMP1 causes a rapid and transient stimulation of the Bcl-2 homologue Mcl-1 levels in B- cell lines. Cancer Res. 56, 4610-4613 (1996). [PubMed: 8840972]

144. D'Souza B, Rowe M \& Walls D The bfl-1 gene is transcriptionally upregulated by the EpsteinBarr virus LMP1, and its expression promotes the survival of a Burkitt's lymphoma cell line. J. Virol 74, 6652-6658 (2000). [PubMed: 10864681]

145. Ko YH Editorial: EBV and human cancer. Exp. Mol. Med 47, e130-3 (2015). [PubMed: 25613727]

146. Collison J Targeting Bcl-2 prevents nephritis in mice. Nat. Rev. Rheumatol 12, 376-376 (2016).

147. American College of Rheumatology., S. P. A. S. C. G. L. O. D. H. C. G. A. S. J. L. S. E. L. O. et al. Arthritis and rheumatism. Arthritis \&amp 66, (J.B. Lippincott Co, 1958).

148. Minocha M, Zeng J, Medema JK \& Othman AA Pharmacokinetics of the B-Cell Lymphoma 2 (Bcl-2) Inhibitor Venetoclax in Female Subjects with Systemic Lupus Erythematosus. Clin. Pharmacokinet 2, 1-14 (2018).

149. Speir M et al. Eliminating Legionella by inhibiting BCL-XL to induce macrophage apoptosis. Nat. Microbiol 1, (2016).

150. Okouchi M, Ekshyyan O, Maracine M \& Aw TY Neuronal apoptosis in neurodegeneration. Antioxid. Redox Signal 9, 1059-96 (2007). [PubMed: 17571960]

151. Radi E, Formichi P, Battisti C \& Federico A Apoptosis and oxidative stress in neurodegenerative diseases. J. Alzheimer's Dis 42, S125-S152 (2014). [PubMed: 25056458]

152. Wright KM \& Deshmukh M Restricting apoptosis for postmitotic cell survival and its relevance to cancer. Cell Cycle 5, 1616-20 (2006). [PubMed: 16880745]

153. Kole a J., Annis RP \& Deshmukh M Mature neurons: equipped for survival. Cell Death Dis. 4, e689 (2013). [PubMed: 23807218]

154. Polster BM, Robertson CL, Bucci CJ, Suzuki M \& Fiskum G Postnatal brain development and neural cell differentiation modulate mitochondrial Bax and $\mathrm{BH} 3$ peptide-induced cytochrome $\mathrm{c}$ release. Cell Death Differ. 10, 365-70 (2003). [PubMed: 12700636]

155. Rohn TT The role of caspases in Alzheimer's disease; Potential novel therapeutic opportunities. Apoptosis 15, 1403-1409 (2010). [PubMed: 20127416]

156. Siegel SJ, Bieschke J, Powers ET \& Kelly JW The oxidative stress metabolite 4-hydroxynonenal promotes Alzheimer protofibril formation. Biochemistry 46, 1503-10 (2007). [PubMed: 17279615] 
157. Jazvinšćak Jembrek M, Hof PR \& Šimić G Ceramides in Alzheimer's Disease: Key Mediators of Neuronal Apoptosis Induced by Oxidative Stress and A $\beta$ Accumulation. Oxid. Med. Cell. Longev 2015, 1-17 (2015).

158. Hoadley KA et al. Cell-of-Origin Patterns Dominate the Molecular Classification of 10,000 Tumors from 33 Types of Cancer. Cell 173, 291-304.e6 (2018). [PubMed: 29625048]

159. Crews L, Rockenstein E \& Masliah E APP transgenic modeling of Alzheimer's disease: Mechanisms of neurodegeneration and aberrant neurogenesis. Brain Struct. Funct 214, 111-126 (2010). [PubMed: 20091183]

160. Kitamura Y et al. Alteration of proteins regulating apoptosis, Bcl-2, Bcl-x, Bax, Bak, Bad, ICH-1 and CPP32, in Alzheimer's disease. Brain Res. 780, 260-269 (1998). [PubMed: 9507158]

161. Rohn TT et al. Lack of Pathology in a Triple Transgenic Mouse Model of Alzheimer's Disease after Overexpression of the Anti-Apoptotic Protein Bcl-2. J. Neurosci 28, 3051-3059 (2008). [PubMed: 18354008]

162. Blesa J \& Przedborski S Parkinson's disease: animal models and dopaminergic cell vulnerability. Front. Neuroanat 8, 155 (2014). [PubMed: 25565980]

163. Wood-Kaczmar A et al. PINK1 Is Necessary for Long Term Survival and Mitochondrial Function in Human Dopaminergic Neurons. PLoS One 3, e2455 (2008). [PubMed: 18560593]

164. Berger AK et al. Parkin selectively alters the intrinsic threshold for mitochondrial cytochrome $\mathrm{c}$ release. Hum. Mol. Genet 18, 4317-28 (2009). [PubMed: 19679562]

165. Wu D et al. Two molecular pathways initiate mitochondria- dependent dopaminergic neurodegeneration in experimental Parkinson 's disease. Proc Natl Acad Sci U S A 104, (2007).

166. Ghavami S et al. Autophagy and apoptosis dysfunction in neurodegenerative disorders. Prog. Neurobiol 112, 24-49 (2014). [PubMed: 24211851]

167. Reyes NA et al. Blocking the mitochondrial apoptotic pathway preserves motor neuron viability and function in a mouse model of amyotrophic lateral sclerosis. Control 120, 3673-3679 (2010).This study demonstrates the functional impact of apoptosis prevention in a mouse model of ALS.

168. Saudou F, Finkbeiner S, Devys D \& Greenberg ME Huntingtin Acts in the Nucleus to Induce Apoptosis but Death Does Not Correlate with the Formation of Intranuclear Inclusions. Cell 95, 55-66 (1998). [PubMed: 9778247]

169. Hickey MA \& Chesselet M-F Apoptosis in Huntington's disease. Prog. NeuroPsychopharmacology Biol. Psychiatry 27, 255-265 (2003).

170. Sagot $\mathrm{Y}$ et al. Bcl-2 overexpression prevents motoneuron cell body loss but not axonal degeneration in a mouse model of a neurodegenerative disease. J Neurosci 15, 7727-7733 (1995). [PubMed: 7472523]

171. Broughton BRS, Reutens DC \& Sobey CG Apoptotic Mechanisms After Cerebral Ischemia. Stroke 40, (2009).

172. Hayakawa $\mathrm{K}$ et al. Transfer of mitochondria from astrocytes to neurons after stroke. Nature 535, 551-555 (2016). [PubMed: 27466127]

173. Plesnila N et al. Function of BID - a Molecule of the bcl-2 Family - in Ischemic Cell Death in the Brain. Eur. Surg. Res 34, 37-41 (2002). [PubMed: 11867899]

174. Gill R et al. Role of Caspase-3 Activation in Cerebral Ischemia-Induced Neurodegeneration in Adult and Neonatal Brain. J. Cereb. Blood Flow Metab 22, 420-430 (2002). [PubMed: 11919513]

175. Gibson ME et al. BAX contributes to apoptotic-like death following neonatal hypoxia-ischemia: evidence for distinct apoptosis pathways. Mol. Med 7, 644-655 (2001). [PubMed: 11778654]

176. Zhang X, Chen Y, Jenkins LW, Kochanek PM \& Clark RSB Bench-to-bedside review: Apoptosis/ programmed cell death triggered by traumatic brain injury. Crit. Care 9, 66-75 (2005). [PubMed: 15693986]

177. RAGHUPATHI R, GRAHAM DI \& McINTOSH TK Apoptosis After Traumatic Brain Injury. J. Neurotrauma 17, 927-938 (2000). [PubMed: 11063058]

178. Kohda K et al. Role of apoptosis induced by Helicobacter pylori infection in the development of duodenal ulcer. Gut 44, 456-62 (1999). [PubMed: 10075950] 
179. Yamasaki E et al. Helicobacter pylori Vacuolating Cytotoxin Induces Activation of the Proapoptotic Proteins Bax and Bak, Leading to Cytochrome $c$ Release and Cell Death, Independent of Vacuolation. J. Biol. Chem 281, 11250-11259 (2006). [PubMed: 16436379]

180. Matsumoto A et al. Helicobacter pylori VacA Reduces the Cellular Expression of STAT3 and Prosurvival Bcl-2 Family Proteins, Bcl-2 and Bcl-XL, Leading to Apoptosis in Gastric Epithelial Cells. Dig. Dis. Sci 56, 999-1006 (2011). [PubMed: 20927590]

181. Strack PR et al. Apoptosis mediated by HIV protease is preceded by cleavage of Bcl-2. Proc. Natl. Acad. Sci. U. S. A 93, 9571-6 (1996). [PubMed: 8790371]

182. Roggero R et al. Binding of Human Immunodeficiency Virus Type 1 gp120 to CXCR4 Induces Mitochondrial Transmembrane Depolarization and Cytochrome c-Mediated Apoptosis Independently of Fas Signaling. J. Virol 75, 7637-7650 (2001). [PubMed: 11462036]

183. Ullrich CK, Groopman JE \& Ganju RK HIV-1 gp120- and gp160-induced apoptosis in cultured endothelial cells is mediated by caspases. Blood 96, 1438-1442 (2000). [PubMed: 10942389]

184. Boudet F, Lecoeur H \& Gougeon ML Apoptosis associated with ex vivo down-regulation of Bcl-2 and up- regulation of Fas in potential cytotoxic CD8+ T lymphocytes during HIV infection. J. Immunol 156, 2282-2293 (1996). [PubMed: 8690919]

185. Cambier CJ, Falkow S \& Ramakrishnan L Host evasion and exploitation schemes of Mycobacterium tuberculosis. Cell 159, 1497-1509 (2014). [PubMed: 25525872]

186. Schulz JB et al. Extended therapeutic window for caspase inhibition and synergy with MK-801 in the treatment of cerebral histotoxic hypoxia. Cell Death Differ. 5, 847-857 (1998). [PubMed: 10203688]

187. Venero JL, Burguillos MA \& Joseph B Caspases Playing in the Field of Neuroinflammation: Old and New Players. Dev. Neurosci 35, 88-101 (2013). [PubMed: 23445938]

188. Clark RS et al. boc-Aspartyl(OMe)-Fluoromethylketone Attenuates Mitochondrial Release of Cytochrome c and Delays Brain Tissue Loss after Traumatic Brain Injury in Rats. J. Cereb. Blood Flow Metab 27, 316-326 (2007). [PubMed: 16736044]

189. Cheng $\mathrm{Y}$ et al. Caspase inhibitor affords neuroprotection with delayed administration in a rat model of neonatal hypoxic-ischemic brain injury. J. Clin. Invest 101, 1992-1999 (1998). [PubMed: 9576764]

190. Han BH et al. Selective, Reversible Caspase-3 Inhibitor Is Neuroprotective and Reveals Distinct Pathways of Cell Death after Neonatal Hypoxic-ischemic Brain Injury. J. Biol. Chem 277, 30128-30136 (2002). [PubMed: 12058036]

191. Niu X et al. A Small-Molecule Inhibitor of Bax and Bak Oligomerization Prevents Genotoxic Cell Death and Promotes Neuroprotection. Cell Chem. Biol 1-14 (2017). doi:10.1016/ j.chembiol.2017.03.011. [PubMed: 28107651] This paper is one of the first reports of small molecules able to bind and inactivate BAX and BAK for potential neuroprotection.

192. Hetz C et al. Bax channel inhibitors prevent mitochondrion-mediated apoptosis and protect neurons in a model of global brain ischemia. J. Biol. Chem 280, 42960-70 (2005). [PubMed: 16219766]

193. Pan R et al. Selective BCL-2 Inhibition by ABT-199 Causes On Target Cell Death in Acute Myeloid Leukemia. Cancer Discov. (2013). doi:10.1158/2159-8290.CD-13-0609

194. Juin P, Geneste O, Gautier F, Depil S \& Campone M Decoding and unlocking the BCL-2 dependency of cancer cells. Nat. Rev. Cancer 13, (2013).

195. Leverson JD et al. Exploiting selective BCL-2 family inhibitors to dissect cell survival dependencies and define improved strategies for cancer therapy. Sci. Transl. Med 7, 279ra40 (2015).

196. Pécot J et al. Tight Sequestration of BH3 Proteins by BCL-xL at Subcellular Membranes Contributes to Apoptotic Resistance. Cell Rep. 17, (2016).

197. Konopleva M et al. Mechanisms of apoptosis sensitivity and resistance to the BH3 mimetic ABT-737 in acute myeloid leukemia. Cancer Cell 10, 375-388 (2006). [PubMed: 17097560]

198. Goldsmith KC et al. Mitochondrial Bcl-2 family dynamics define therapy response and resistance in neuroblastoma. Cancer Res. 72, 2565-77 (2012). [PubMed: 22589275] 
199. Roberts AW et al. Targeting BCL2 with Venetoclax in Relapsed Chronic Lymphocytic Leukemia. N. Engl. J. Med 151206090218007 (2015). doi:10.1056/NEJMoa1513257.This study provides a demonstration of the clinical utility of BH3 mimetics for the treatment of cancer.

200. Schenk RL, Strasser A \& Dewson G BCL-2: Long and winding path from discovery to therapeutic target. Biochem. Biophys. Res. Commun 482, 459-469 (2017). [PubMed: 28212732]

201. Letai A S63845, an MCL-1 Selective BH3 Mimetic: Another Arrow in Our Quiver. Cancer Cell 30, 834-835 (2016). [PubMed: 27960083]

202. Vogler $\mathrm{M}$ et al. BCL2/BCL-X(L) inhibition induces apoptosis, disrupts cellular calcium homeostasis, and prevents platelet activation. Blood 117, 7145-54 (2011). [PubMed: 21562047]

203. Al-harbi S et al. An antiapoptotic BCL-2 family expression index predicts the response of chronic lymphocytic leukemia to ABT-737. Blood 118, 3579-3590 (2011). [PubMed: 21772052]

204. Slee E a, Keogh, S. a \& Martin, S. J. Cleavage of BID during cytotoxic drug and UV radiationinduced apoptosis occurs downstream of the point of Bcl-2 action and is catalysed by caspase-3: a potential feedback loop for amplification of apoptosis-associated mitochondrial cytochrome $\mathrm{c}$ release. Cell Death Differ. 7, 556-65 (2000). [PubMed: 10822279]

205. Suzuki Y et al. A serine protease, HtrA2, is released from the mitochondria and interacts with XIAP, inducing cell death. Mol. Cell 8, 613-621 (2001). [PubMed: 11583623]

206. Srinivasula SM et al. A conserved XIAP-interaction motif in caspase- 9 and Smac/DIABLO regulates caspase activity and apoptosis. Nature 410, 112-116 (2001). [PubMed: 11242052]

207. Toshiyuki M \& Reed JC Tumor suppressor p53 is a direct transcriptional activator of the human bax gene. Cell 80, 293-299 (1995). [PubMed: 7834749]

208. Zong WX, Edelstein LC, Chen C, Bash J \& Gélinas C The prosurvival Bcl-2 homolog Bfl-1/A1 is a direct transcriptional target of NF-kappaB that blocks TNFalpha-induced apoptosis. Genes Dev. 13, 382-7 (1999). [PubMed: 10049353]

209. Grossmann $\mathrm{M}$ et al. The anti-apoptotic activities of Rel and RelA required during B-cell maturation involve the regulation of Bcl-2 expression. EMBO J. 19, 6351-60 (2000). [PubMed: 11101508]

210. Kale J, Osterlund EJ \& Andrews DW BCL-2 family proteins: changing partners in the dance towards death. Cell Death Differ. 25, 65-80 (2017). [PubMed: 29149100]

211. Chi X, Kale J, Leber B \& Andrews DW Regulating cell death at, on, and in membranes. Biochim. Biophys. Acta (2014). doi:10.1016/j.bbamcr.2014.06.002

212. Kalkavan H \& Green DR MOMP, cell suicide as a BCL-2 family business. Cell Death Differ. 25, 1-10 (2017).

213. Popgeorgiev N, Jabbour L \& Gillet G Subcellular Localization and Dynamics of the Bcl-2 Family of Proteins. Front. Cell Dev. Biol 6, 1-11 (2018). [PubMed: 29417046]

214. Gavathiotis E et al. BAX activation is initiated at a novel interaction site. Nature 455, 1076-81 (2008). [PubMed: 18948948]

215. Brahmbhatt H, Uehling D, Al-awar R, Leber B \& Andrews D Small molecules reveal an alternative mechanism of Bax activation. Biochem. J 0, 1073-1083 (2016).

216. Chonghaile Ni \& Sarosiek K et al. Supplemenary Material: Pretreatment mitochondrial priming correlates with clinical response to cytotoxic chemotherapy. Science 334, 1129-33 (2011). [PubMed: 22033517]

217. Ryan J, Montero J, Rocco J \& Letai A iBH3: simple, fixable BH3 profiling to determine apoptotic priming in primary tissue by flow cytometry. Biol. Chem 0, (2016).

218. Davids MS et al. Mitochondrial Apoptotic Priming Is Associated with Clinical Response to the Bcl-2 Antagonist ABT-199 in Chronic Lymphocytic Leukemia. 2014 1940, (124AD).

219. Vo T-T et al. Relative Mitochondrial Priming of Malignant Myeloblasts and Normal HSCs Determines Chemotherapeutic Success in AML. Cell 151, 344-355 (2012). [PubMed: 23063124]

220. Del V et al. BCL-2 dependence and ABT-737 sensitivity in acute lymphoblastic leukemia BCL-2 dependence and ABT-737 sensitivity in acute lymphoblastic leukemia. Leukemia 111, 23002309 (2008). 
221. Ni Chonghaile T et al. Maturation Stage of T-cell Acute Lymphoblastic Leukemia Determines BCL-2 versus BCL-XL Dependence and Sensitivity to ABT-199. Cancer Discov. 4, 1074-1087 (2014). [PubMed: 24994123]

222. Deng J et al. BH3 profiling identifies three distinct classes of apoptotic blocks to predict response to ABT-737 and conventional chemotherapeutic agents. Cancer Cell 12, 171-85 (2007). [PubMed: 17692808]

223. Montero J et al. Drug-Induced Death Signaling Strategy Rapidly Predicts Cancer Response to Chemotherapy. Cell 160, 977-989 (2015). [PubMed: 25723171]

224. Montero J et al. Blastic Plasmacytoid Dendritic Cell Neoplasm is Dependent on BCL-2 and Sensitive to Venetoclax. Cancer Discov. (2016). doi:10.1158/2159-8290.CD-16-0999 
Box 1:

BH3 mimetics under development 


\section{Promoters of apoptosis}

\section{Pro-survival $B C L-2$ family protein inhibitors (e.g. BAD mimetics)}

\section{BCL-2}

$B C L-W$

$B C L-X_{L}$

BFL1

MCL1

Direct activators of BAX or BAK (e.g. BIM mimetics)

$\mathrm{BAX}$

BAK

\section{Inhibitors of apoptosis}

\section{Direct inhibitors of BAX or BAK (e.g. BCL-X mimetics)}

$\mathrm{BAX}$

BAK

As outlined in this Review, modulating cell death can have a potentially profound impact on the treatment of many human diseases, especially cancers. The recent development of novel small-molecule inhibitors of pro-survival proteins from the BCL-2 family, called BH3 mimetics, enables the direct and selective activation of mitochondrial apoptosis in cells that are highly dependent on one or more pro-survival proteins (due to inherent or stress-induced signalling). These agents work by inhibiting the activity of pro-survival proteins (see figure) and, in the process, freeing any pro-apoptotic protein that is actively being sequestered. The pro-apoptotic protein is then able to carry out its primary function in activating apoptosis (see also Fig. 4$)^{74}$.

The US Food and Drug Administration recently approved the BCL-2 inhibitor venetoclax (ABT-199) for use in chronic lymphocytic leukaemia based on its excellent clinical activity, including in patients that have relapsed after multiple rounds of therapy and those with mutated p53 (ref. ${ }^{199}$ ). Agents targeting other major pro-survival proteins 
(BCL- $\mathrm{X}_{\mathrm{L}}$ and MCL1) are also undergoing clinical evaluation ${ }^{74,200,201}$. Although these agents have already shown great potential in haematologic cancers, their deployment in solid cancers and non-malignant diseases has been challenging due to an insufficient understanding of apoptotic dependencies and how to identify and exploit them in the clinic safely and effectively.

Although these agents have on-target toxicities that can be managed clinically (such as thrombocytopenia due to platelet apoptosis in response to BCL- $\mathrm{X}_{\mathrm{L}}$ inhibition ${ }^{202}$ ) they would ideally be administered to patients with cancers that are dependent on the specific pro-survival protein being inhibited to avoid unnecessary toxicity and maximize activity. As one might expect, the expression level of a pro-survival protein within cells is not itself a strong predictor of whether apoptosis will occur upon its inhibition ${ }^{203}$ since it is the active sequestration of pro-apoptotic molecules that ultimately determine response, which is more difficult to ascertain. This is particularly true of clinical biopsy specimens, which are most commonly formalin fixed and paraffin embedded, making most biochemical and functional assays impossible. However, the clinical development of these agents is being complemented by intense research and development of the biomarkers that may guide their use.

As highlighted throughout this Review, there are exciting opportunities to block apoptosis for potential therapeutic benefit. The recent development of small molecule inhibitors of BAX and BAK may finally enable clinical evaluation of this novel class of agents. It may be expected that blocking apoptosis could help facilitate tumorigenesis since preneoplastic cells would not die in response to accumulating DNA damage but we envision that inhibitors of BAX and BAK would not be used chronically. We would propose that transient inhibition of apoptosis may give cells an additional opportunity to repair DNA damage or re-establish protein homeostasis and return to an optimal, healthy state - this, however, needs to be formally tested in animal models or clinically. Overall, as the understanding of the BCL-2 family regulation advances beyond cancer, agents such as those shown in the figure, both positive and negative regulators of apoptosis, may be extended for therapeutic use in non-malignant diseases as proposed in this Review. 


\section{Box 2:}

\section{Regulation of BCL-2 proteins}

Although the final decision of whether a cell should undergo apoptosis is binary and switch-like, the regulation of BCL-2 family proteins is graded and highly complex. Multiple positive feedback loops ensure that when the balance of BCL-2 family proteins shifts toward apoptosis, it cannot be reversed. For example, activated caspases cleave and activate $\mathrm{BID}^{204}$ to facilitate further BAX/BAK activation to ensure that mitochondrial outer membrane permeabilization (MOMP) is complete and irreversible. In turn, the inhibition of XIAP by SMAC and OMI following MOMP fuels rapid and potent caspase activation ${ }^{205,206}$. Ultimately, cellular susceptibility to apoptosis is determined by the abundance, stability, activity and localization of BCL-2 family proteins. Levels of BCL-2 family proteins are, in large part, determined by their transcriptional regulation. For example, transcription of pro-apoptotic $B A X$ mRNA is regulated by p53 (ref. ${ }^{207}$ ) and $\mathrm{Myc}^{46,93}$ (see also Fig. 2a) to drive apoptotic competence in damaged or highly proliferative cells, respectively. Similarly, transcription factors typically associated with immune cell activation such as NF- $\mathrm{\kappa B}$ and STAT3 can upregulate BFL1 (ref. ${ }^{208}$ ) and BCL-2 (ref. ${ }^{209}$ ), respectively, to help promote cell survival, which likely supports immune system homeostasis and facilitates immune responses. This transcriptional regulation is balanced by protein degradation via the ubiquitin-proteasome system ${ }^{210}$. In addition, BCL-2 protein activity can be affected by interactions with other proteins including interaction between BCL-2 family members (see Fig. 2a) as well interactions various non-BCL-2 family proteins - and by various post-translational modifications (these topics have been recently reviewed elsewhere ${ }^{34,210-212}$ ). Moreover, because the loss of mitochondrial outer membrane integrity is the key cellular event committing the cell to apoptosis, the regulation of pro-apoptotic protein localization to this membrane needs to be tightly regulated ${ }^{213}$. The regulation of BCL-2 family proteins at the mitochondrial surface has been comprehensively reviewed elsewhere (see ${ }^{121,210}$ ). A prominent example is the regulation of $\mathrm{BAX}$ and $\mathrm{BCL}-\mathrm{X}_{\mathrm{L}}$, which are continuously shuttled between the mitochondrial membrane and the cytosol. BAX thus seemingly requires a two-step activation system: the first step induces a change in BAX conformation by the binding of a pro-apoptotic $\mathrm{BH} 3$ domain to a non-canonical binding site and recruits it to the mitochondrial surface 214,215 ; the second step enables BAX to oligomerize and form pores in the mitochondrial outer membrane ${ }^{35}$. The redundant levels of regulation help ensure that apoptosis only occurs when intended, helping to maintain organismal homeostasis. Importantly, the ways in which each of the BCL-2 family proteins is regulated can vary in different physiological contexts and in disease, as described in this Review. 


\section{Box 3:}

\section{BH3 profiling and its applications}

Due to the large number of BCL-2 family proteins, their complex interactions and posttranslational modifications, it is difficult to measure the apoptosis sensitivity of cells via biochemical approaches. The $\mathrm{BH} 3$ profiling assay overcomes this by functionally tracking cellular responses to pro-apoptotic signals delivered directly to the BCL-2 family proteins at the mitochondria. This integrated measure avoids the need for quantitation of individual BCL-2 family proteins and can be used as a platform to test several important parameters.

\section{Measuring the level of apoptotic priming within healthy or diseased cells and} tissues.

Cells differ in their sensitivity to apoptosis, ranging along a continuum that is defined from being primed for apoptosis (highly sensitive) to being apoptosis refractory (unable to undergo apoptotic cell death) 44,46,75,216,217 (see also Fig. 2b). Apoptotic priming defines how close cells are to the threshold of apoptosis. Due to the complexity in regulation of BCL-2 family proteins and the varied upstream signalling pathways activated by stress or damage, delivering a dose of pro-apoptotic signals directly to mitochondria is the only manner in which measurement of apoptotic priming can be made accurately. Such measurements have been previously used to identify apoptotic priming as a major determinant of cancer responses to chemotherapy in the clinic $^{216,218,219}$ as well as healthy tissue responses to ionizing radiation and chemotherapy ${ }^{46}$.

\section{Measuring cellular dependence on specific pro-survival proteins.}

Certain BH3 peptides, which mimic the activity of sensitizer BH3-only proteins, have very specific interactions with pro-survival proteins (see also Fig. 2a). For example, the BAD BH3 peptide inhibits BCL-2, BCL- $\mathrm{X}_{\mathrm{L}}$ and BCL-w, whereas the Hrk BH3 peptide only inhibits BCL- $\mathrm{X}_{\mathrm{L}}$. Using these peptides, the dependence of a given cell on any of the pro-survival proteins can be directly assessed by measuring the extent of cytochrome $\mathrm{c}$ loss in response to $\mathrm{BH} 3$ peptides derived from sensitizer proteins. These measurements have been used to identify dependencies on pro-survival proteins in chronic lymphocytic leukaemias (BCL-2) ${ }^{193,220}$, certain acute myeloid leukaemias (BCL-2), subtypes of healthy $\mathrm{T}$ cells and their transformed counterparts (BCL-2 or BCL- $\mathrm{X}_{\mathrm{L}}{ }^{221}$ ), and multiple myelomas (MCL1 and BCL-2).

\section{Uncovering novel interaction dynamics among apoptosis-regulating proteins.}

The direct application of $\mathrm{BH} 3$ domain peptides to monitored mitochondria allows for the careful dissection of interaction dynamics between BCL-2 family proteins. This has previously been used to characterize the selectivity of $\mathrm{BH} 3$ domains and the proteins that bear them for their pro-survival interaction partners ${ }^{21}$ or pro-apoptotic effectors ${ }^{41}$.

Predicting how patients will respond to chemotherapy in the clinic. 
The level of apoptotic priming within a tumour cell prior to therapy can be a major determinant of therapy response ${ }^{216}$. $\mathrm{BH} 3$ profiling has been shown to have potential clinical utility to predict how patients respond to both cytotoxic chemotherapies ${ }^{216,222,223}$ as well as personalized use of $\mathrm{BH} 3$ mimetics ${ }^{193,224}$. 


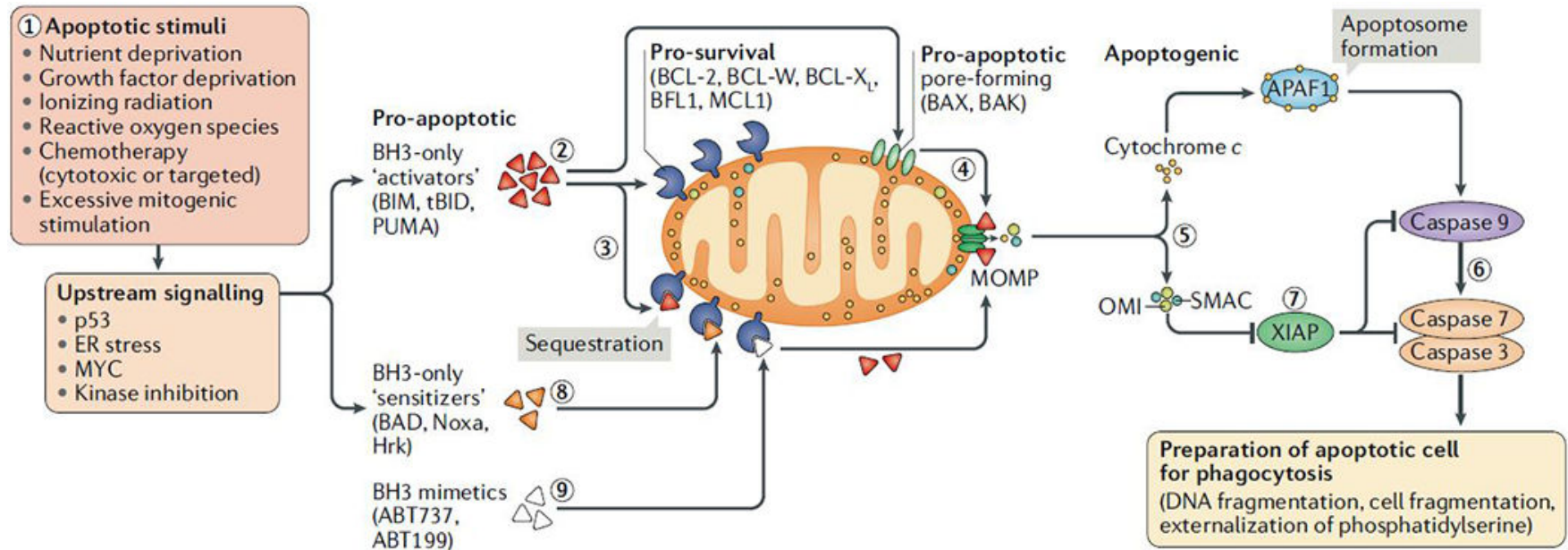

Figure 1: The mitochondrial apoptosis pathway.

To initiate apoptosis, cellular stress or damage signals [1] unleash pro-apoptotic proteins (BH3-only 'activators' of apoptosis) via their upregulation (BIM or PUMA) or cleavage (BID cleaved to form truncated tBID) [2], which can either be bound and sequestered by pro-survival proteins such as BCL-2, BCL-X $\mathrm{L}_{\mathrm{L}}$ or MCL1 [3] or, when these pro-survival proteins are saturated or absent, can activate BAX and/or BAK [4]. Activated BAX or BAK oligomerize and form pores to cause mitochondrial outer membrane permeabilization (MOMP), resulting in the release of apoptogenic molecules including SMAC, OMI and cytochrome $\mathrm{c}$ from the mitochondrial intermembrane space. Cytochrome $\mathrm{c}$ binds APAF1 in the cytosol to form the apoptosome (5), which serves as a platform for the activation of caspase 9, which then goes on to activate the effector caspases 3 and 7 (6) to dismantle the cell and prepare it for phagocytosis. Caspase activation can be blocked by XIAP (7), which in turn is inhibited by the released SMAC and OMI proteins from mitochondria (7).

Upstream damage or stress signalling can also activate BH3-only 'sensitizer' proteins that don't efficiently activate BAX and BAK but inhibit the activity of pro-survival BCL-2 family proteins to release any sequestered $\mathrm{BH} 3$-only activators, which trigger MOMP (8). BH3 mimetics are a novel class of agents that are able to sensitize cells to apoptosis by blocking the activity of pro-survival BCL-2 family proteins (9). 

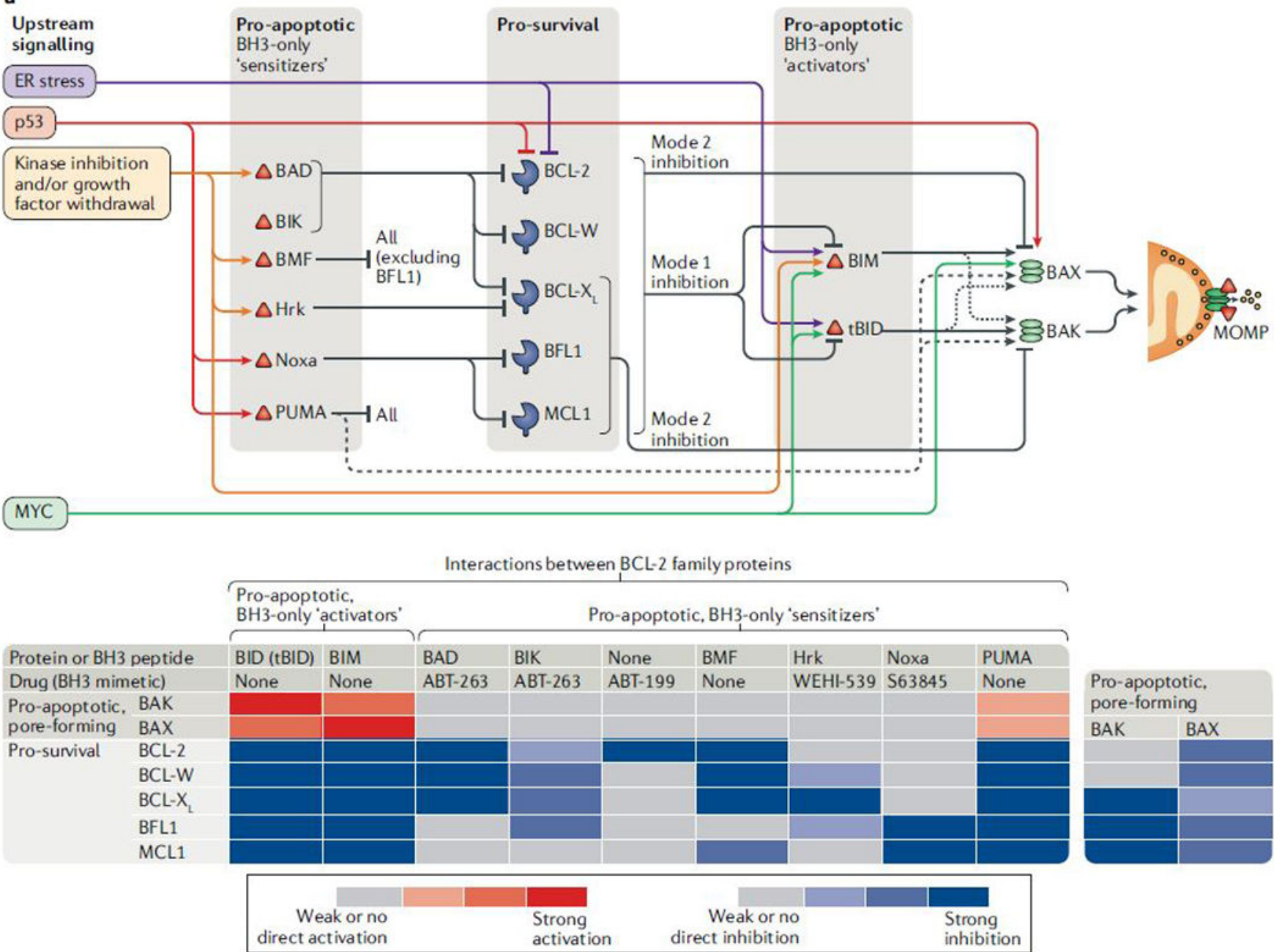


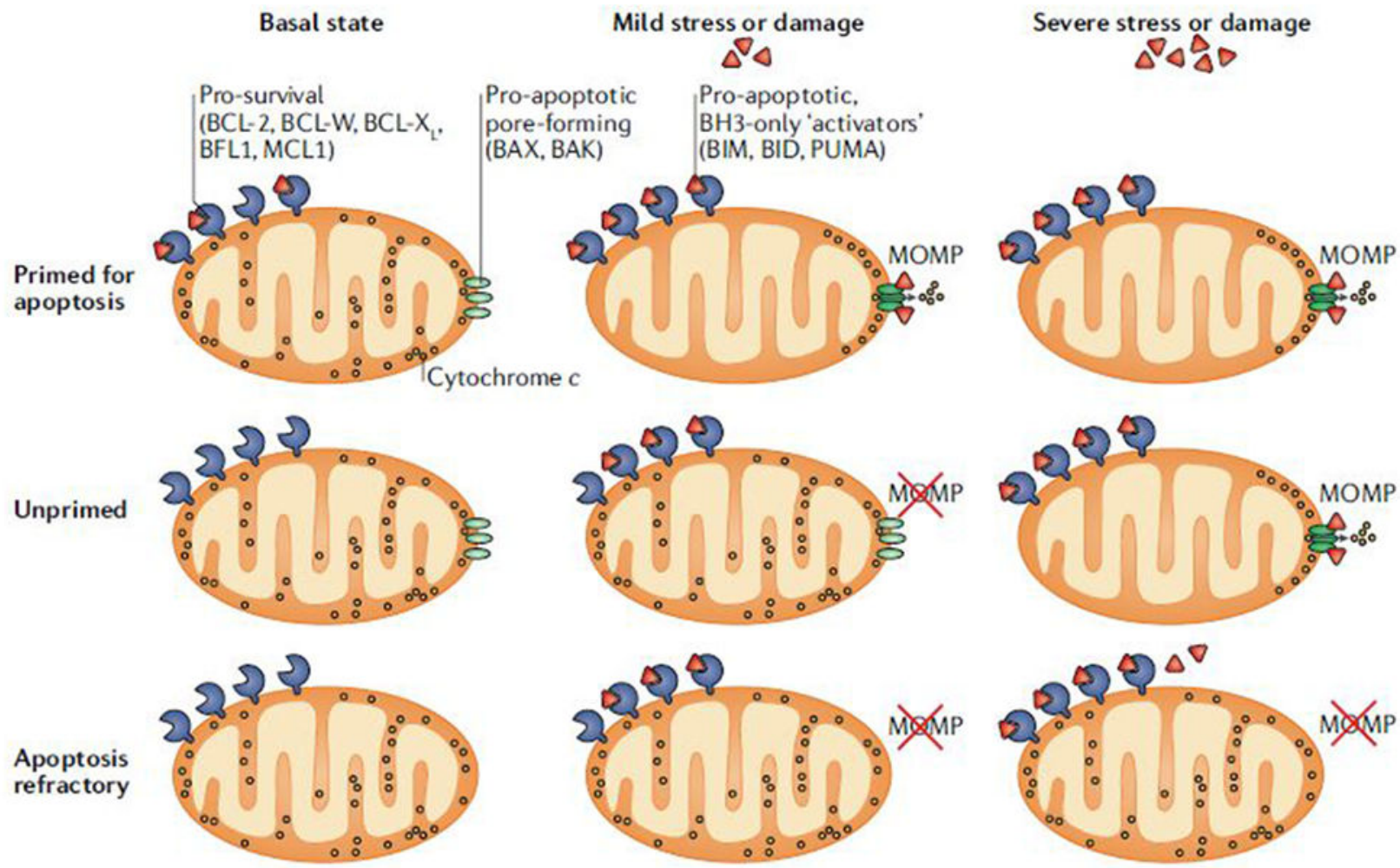

Figure 2: Interactions among BCL-2 family proteins and apoptotic priming.

(a) BCL-2 family proteins interact in several key ways. BH3-only 'activator' proteins (BIM, tBID and to a lesser extent PUMA (dashed lines)) can activate BAX or BAK to result in mitochondrial permeabilization (tBID most efficiently activates BAK, whereas BIM shows stronger affinity for BAX). However, pro-survival proteins can also bind and sequester the activator BH3-only proteins via Mode 1 inhibition. BH3-only 'sensitizer' proteins can bind and inactivate specific pro-survival proteins, which would result in the release of any BH3only activators that are actively being sequestered. Finally, pro-survival proteins can also bind and sequester BAX or BAK directly via Mode 2 inhibition, preventing their oligomerization. Damage and stress-induced signalling pathways trigger apoptosis via distinct mechanisms involving modulation of the expression levels or activity of BCL-2 family proteins. The table below is a graphic depiction of the different interactions and their affinities established between BCL-2 family proteins. These different interactions result in differential regulation of apoptosis, depending on expression levels of the different components. In addition, BH3 mimetics of sensitizer proteins can be used to further modify the BCL-2 protein interactome. (b) Cells can exhibit widely differing susceptibility to apoptosis. Cells which are primed for apoptosis express high levels of pro-apoptotic activator proteins at a basal state and even a mild stress, which causes a modest increase in the expression of pro-apoptotic factors, will trigger mitochondrial outer membrane permeabilization (MOMP). Unprimed cells can activate apoptosis, but require more damage or stress to overwhelm pro-survival proteins that are not actively sequestering pro-apoptotic molecules. Finally, cells that are apoptosis refractory do not express sufficient levels of the pro-apoptotic pore-forming proteins BAX or BAK and are unable to trigger MOMP even under severe stress. 

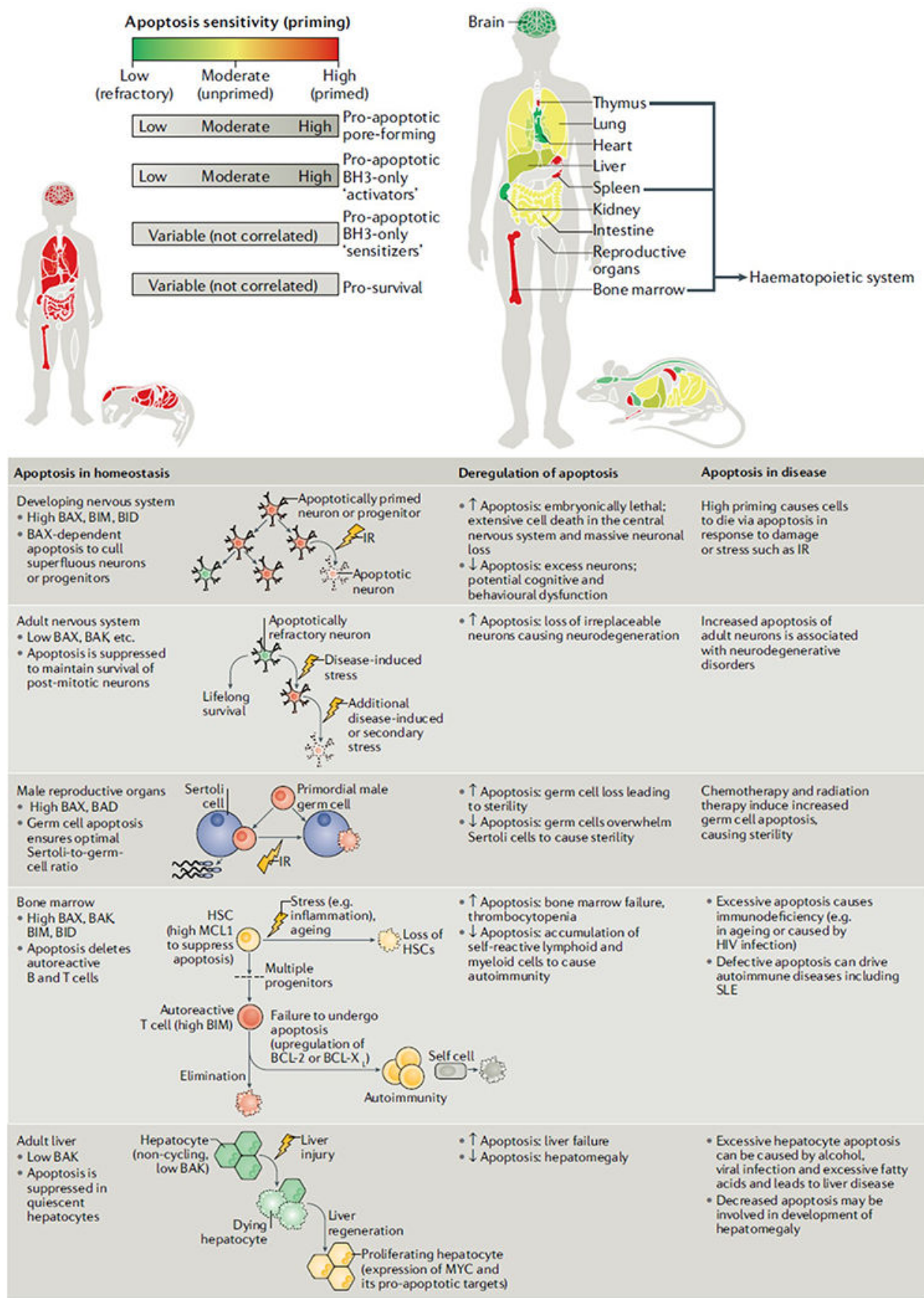

Figure 3: Apoptosis and apoptotic priming in physiology.

Apoptosis is differently and dynamically regulated across mammalian lifespan. Tissues that are highly proliferative or have the potential to become highly proliferative (developing tissues, adult haematopoietic system) are typically primed for apoptosis (red). High apoptotic priming in these tissues makes them highly sensitive to various insults. Tissues that are largely post-mitotic are apoptosis refractory (green), whereas tissues that are characterized as unprimed (such as gastrointestinal system and lungs of adults) (yellow) typically contain highly heterogeneous cell types that may differ in apoptosis sensitivity at a 
cell by cell level. The level of priming within cells or tissues is dependent on the expression of BCL-2 family proteins, with the strongest determinants being expression of the proapoptotic, pore-forming molecules BAX and BAK. Pro-survival and sensitizer BH3-only proteins can be expressed at variable levels and are not as clearly associated with a specific level of priming. Changes in the levels of BCL-2 proteins will, inevitably, impose changes on apoptotic susceptibility, leading to increased or insufficient apoptosis, which can result in pathology. HSC, haematopoietic stem cell; IR, ionizing radiation. 
a
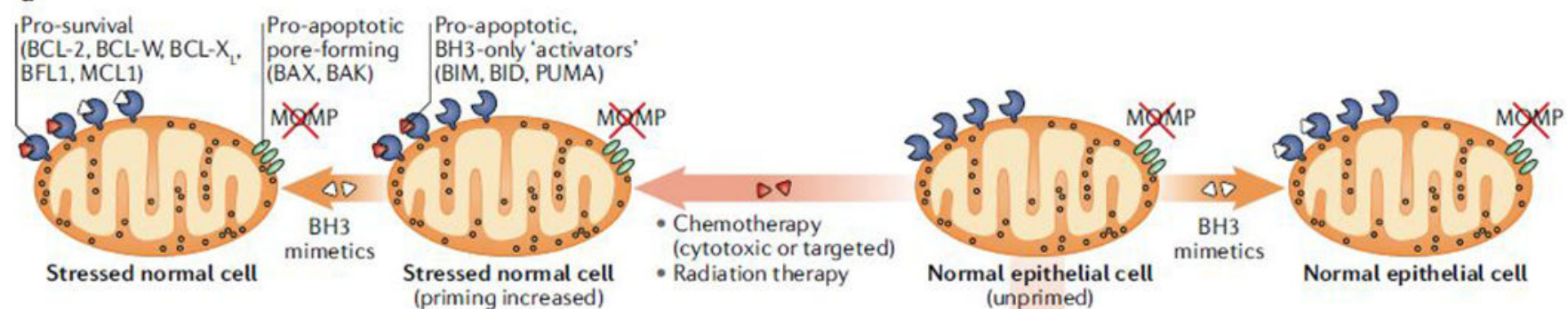

Transformation (MYC deregulation, checkpoint violation,

DNA damage)

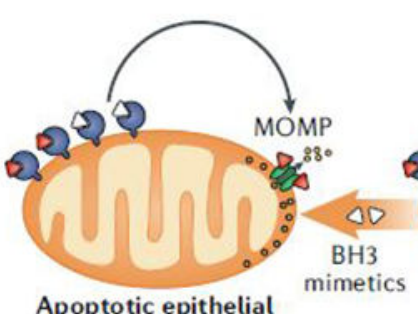

Apoptotic epithelia
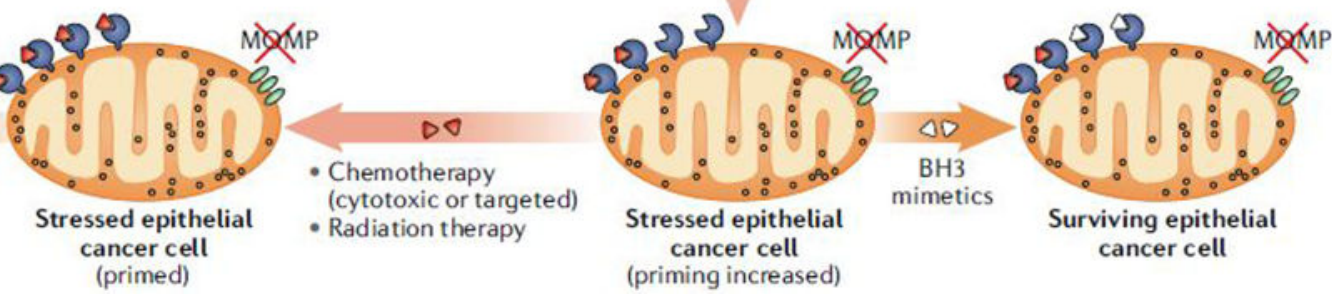

Surviving epithelial cancer cell 
b

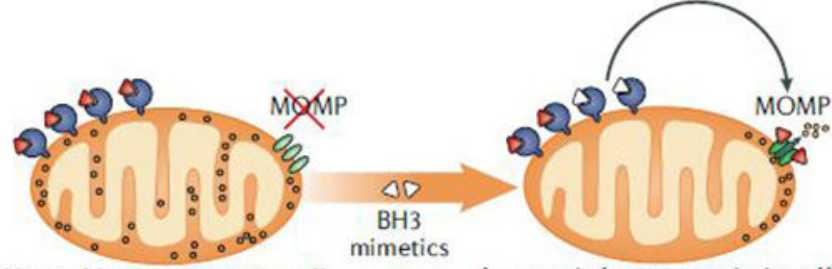

Normal haematopoietic cell (highly primed)

Apoptotic haematopoietic cell
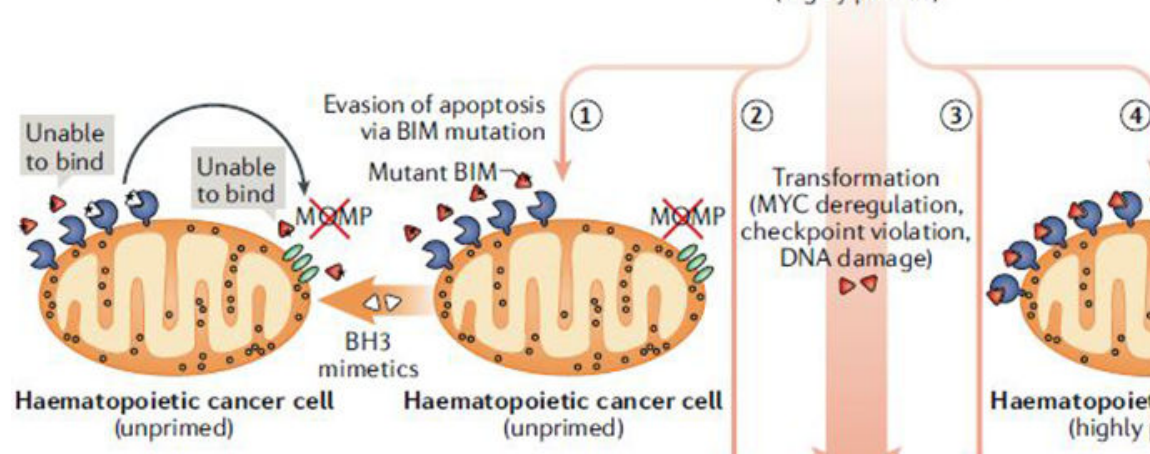

Evasion of apoptosis

Haematopoietic cancer cell

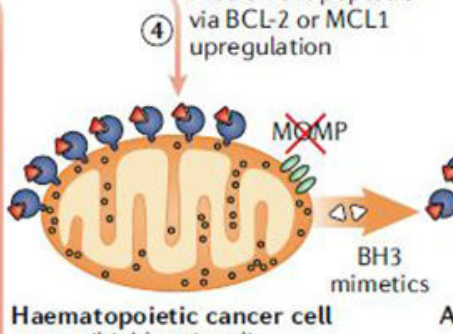

via $\mathrm{BCL}-2$ or $\mathrm{MCL}$

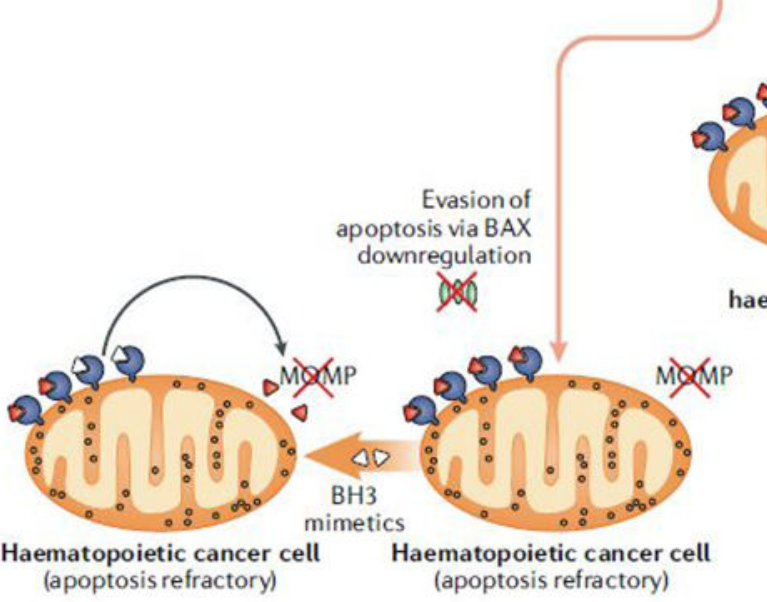
(highly primed)

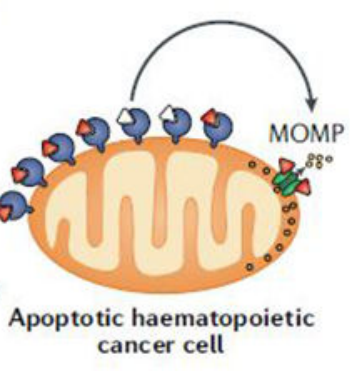

Figure 4: Apoptotic dependencies in cancer cells and their responsiveness to therapy.

(a) During the process of neoplastic transformation, oncogene-driven abnormal growth signals and cell-cycle checkpoint violation [G] leads to cellular stress and upregulation of pro-apoptotic proteins. This upregulation results in higher apoptotic priming of malignant cells at the basal state than normal cells. Because healthy adult tissues are mostly refractory to apoptosis or unprimed (see also Fig. 3), this increase in apoptotic priming of aberrant cells can be exploited therapeutically using BH3 mimetics, in particular when combined with standard anti-cancer therapies such as radiation or chemotherapy. (b) Haematopoietic cells are naturally highly primed for apoptosis. Hence, oncogenic stress and resulting upregulation of pro-apoptotic factors frequently results in the removal of pre-malignant cells derived from this lineage (middle arrow). Several mechanisms associated with BCL-2 protein deregulation, including BIM mutations (1), downregulation of BAX (2) or BIM (3) and upregulation of BCL-2 or MCL1 (4) support the emergence of haematopoietic cancers, which depend on these mechanisms for their survival. Notably, these mechanisms are mainly employed to keep malignant cells alive and haematopoietic cancers typically remain primed for apoptosis and hence are susceptible to therapy and respond well to treatments with $\mathrm{BH} 3$ 
mimetics. However, certain mechanisms, including mutations of sensitizer proteins (1) and downregulation of mitochondrial outer membrane permeabilization (MOMP) pore-forming components (2) yield cells that are unprimed or even apoptosis refractory, and hence resistant to therapies. Solid tumours can employ similar mechanisms to boost their survival, but these dependencies are much less pronounced than in haematopoietic cancers.

Nevertheless, these mechanisms may underlie the development of resistance to treatment and disease relapse. 